\title{
COMPARISON OF REGULAR RINGER'S SOLUTION AND GLUCOSE RINGER'S SOLUTION ON THE LONGEVITY OF THE HIRUDO MEDICINALIS' RETZIUS CELL
}

\author{
A Thesis \\ presented to \\ the Faculty of California Polytechnic State University, \\ San Luis Obispo \\ In Partial Fulfillment \\ of the Requirements for the Degree \\ Master of Science in BioMedical Engineering \\ by
}

Nicole Arielle Peretti

March 2015 
(C) 2015

Nicole Arielle Peretti

ALL RIGHTS RESERVED 
TITLE:

AUTHOR:

DATE SUBMITTED:

COMMITTEE CHAIR:

COMMITTEE MEMBER:

COMMITTEE MEMBER:
Comparison of Regular Ringer's Solution and

Glucose Ringer's Solution on the Longevity of the Hirudo medicinalis' Retzius Cell

Nicole Arielle Peretti

March 2015

Dr. Robert B. Szlavik, Ph.D.

Professor of Biomedical Engineering

Dr. David S. Clague, Ph.D.

Professor of Biomedical Engineering

Dr. Christy Strand, Ph.D.

Associate Professor of Biology 


\begin{abstract}
Comparison of Regular Ringer's Solution and Glucose Ringer's Solution on the Longevity of the Hirudo medicinalis' Retzius Cell
\end{abstract}

Nicole Arielle Peretti

In 1882, Sydney Ringer, a professor of medicine at University College in London, experimented with the frog ventricle to better understand how each constituent of blood influences contraction. The ultimate goal was to create an artificial circulating fluid to use for the perfusion of isolated organs, in this case, a frog heart. Today, Ringer's solution is still used in research for physiological studies requiring the survival and maintenance of specimens outside of their host bodies. One such example is the use of medicinal leech ganglia for electrophysiological measurements. In this thesis, I am comparing two Ringer's solutions, original versus added glucose, and their impact on the longevity of the ganglia. By stimulating cells in the dissected ganglia submerged in Ringer's solution with a micropipette, action potential responses can be recorded and used to compare longevity of the cells in each solution. By providing the dissected ganglia with an additional source of fuel, I hypothesized that cells in the glucose-enriched Ringer's solution would live longer, and thus provide action potentials longer, than cells in regular Ringer's solution with a minimum increase in longevity of thirty minutes. Data analysis showed that glucose Ringer's solution did not keep the cells alive longer than regular Ringer's solution when the difference of means was set to 30 minutes. However, data did show a significant difference in the average longevity of the Retzius cell in glucose Ringer's solution versus regular Ringer's solution when the difference of means was set to zero. 


\section{ACKNOWLEDGMENTS}

Dr. Robert Szlavik

Dr. Christy Strand

Kyle Fast

Zecari Tempesta

Chandra Miller

Linda Mayo

Enrique Ivers

Dr. David Clague 


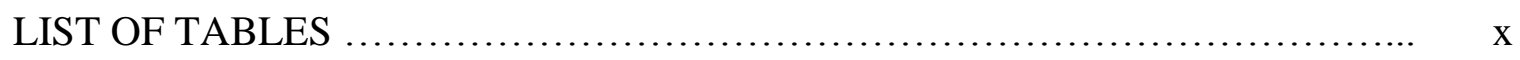

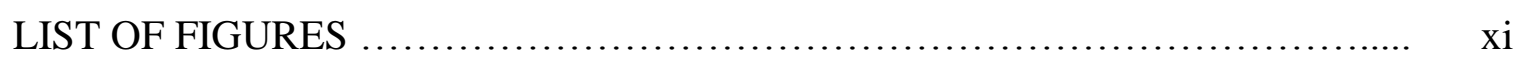

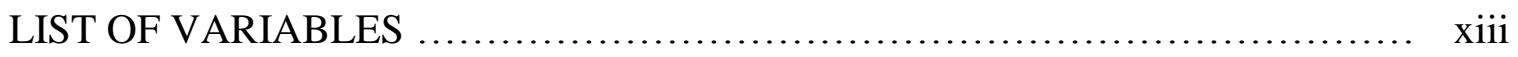
CHAPTER

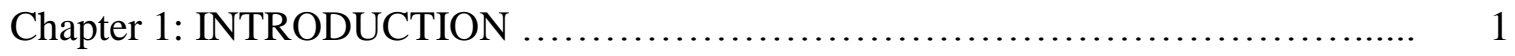

Chapter 2: RINGER'S SOLTUION ........................................ 3

2.1 Sydney Ringer ................................................... 3

2.2 Modification to Ringer's Solution ................................ 9

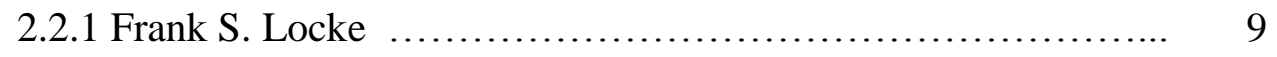

2.2.2 Maurice Vejux Tyrode ................................... 10

2.2.3 Alexis F Hartmann ........................................ 10

2.3 Ringer's Solution Today ................................................ 11

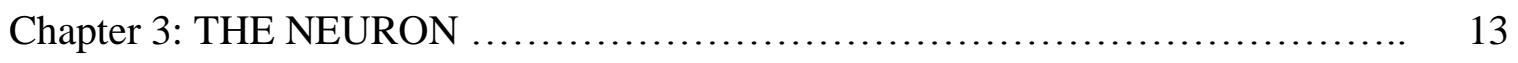

3.1 The Nervous System ........................................... 13

3.2 Neuron Structure ................................................ 14

3.2.1 The Cell Body …...................................... 14

3.2.2 Dendrites ............................................. 15

3.2.3 The Axon ............................................ 15

3.2.4 Axon Terminals .......................................... 15

3.2.5 Synapses ............................................... 16

3.3 Cellular Membrane ............................................. 16

3.3.1 Ion Channels .......................................... 18

3.3.2 Transporters …....................................... 18

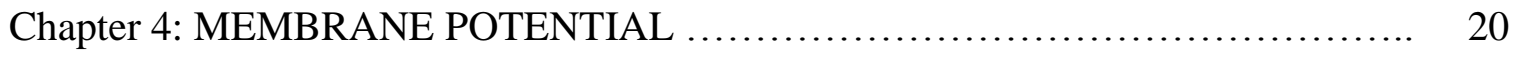

4.1 Intracellular and Extracellular Environments ....................... 20 
4.2 Resting Membrane Potential ...................................... 21

4.2.1 Electrochemical Gradient ................................ 21

4.2.2 Sodium-Potassium Pump ................................. 22

4.2.3 Ion Permeability and Regulation ........................... 23

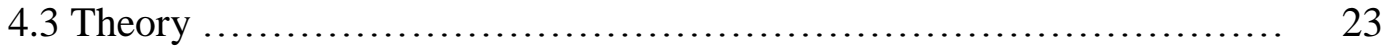

4.3.1 Nernst Equation ........................................ 23

4.3.2 Goldmann Equation ..................................... 25

Chapter 5: THE ACTION POTENTIAL _.................................... 26

5.1 Action Potential Overview ............................................ 26

5.2 Permeability during an Action Potential ............................. 26

5.2.1 Voltage-Dependent Sodium Channels ...................... 26

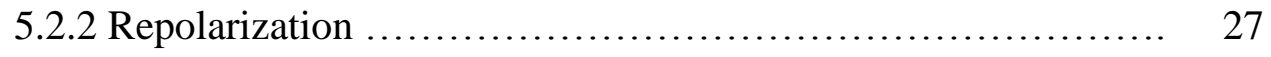

5.3 Phases of an Action Potential ......................................... 29

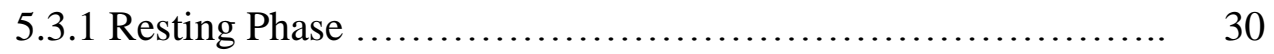

5.3.2 Depolarization Phase .................................... 30

5.3.3 Repolarization Phase .................................... 30

5.3.4 Hyperpolarization Phase .................................... 31

Chapter 6: CELLULAR RESPIRATION AND CELL SURVIVAL ............... 32

6.1 Synthesis of ATP .............................................. 33

6.1.1 Glycolysis ................................................... 33

6.1.2 Krebs Cycle ............................................. 34

6.1.3 Electron Transport Chain ................................ 34

6.2 Surviving Cells in vitro .............................................. 35

Chapter 7: RINGER'S SOLUTION PREPARATIONS ......................... 37

7.1 Regular Ringer's Solution ....................................... 37

7.2 Glucose Ringer's Solution .................................... 38

Chapter 8: HIRUDO MEDICINALIS AND DISSECTION PROTOCOL ........... 40

8.1 Hirudo Medicinalis .............................................. 40 
8.1.1 Leech Anatomy ............................................ 40

8.1.2 Leech Nervous System ................................... 41

8.1.3 Cell Selection ............................................... 43

8.2 Leech Care ..................................................... 43

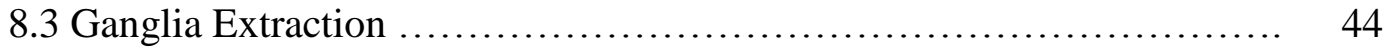

8.3.1 Ganglia Extraction Tools .................................. 44

8.3.2 Ganglia Extraction Procedure ............................. 45

Chapter 9: ELECTROPHYSIOLOGICAL OVERVIEW AND EXPERIMENTAL

PROTOCOLS .............................................................. 51

9.1 Electrophysiological Recording Techniques ........................ 51

9.1.1 Voltage Clamp ......................................... 51

9.1.2 Current Clamp ......................................... 53

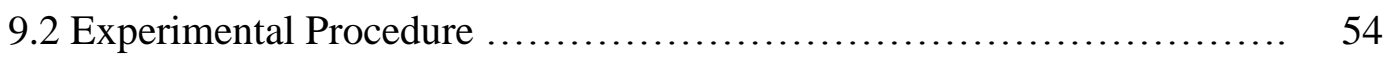

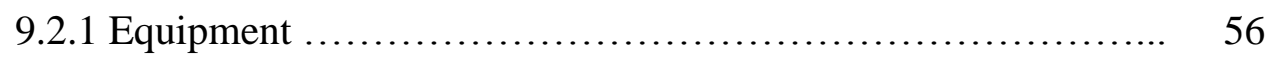

9.2 .2 Equipment Setup ..................................... 56

9.2.3 Electrodes and Noise Reduction ......................... 58

9.2.4 Micropipette Preparation ............................... 58

9.2.5 Calibration Protocol ….................................. 59

9.2.6 Cell Recording Implementation ........................... 62

9.3 Stimulation and Action Potential Recruitment Parameters ............... 65

Chapter 10: RESULTS AND CONCLUSIONS _............................... 66

10.1 Action Potential Recordings ................................... 66

10.2 Survival Time of Retzius Cells in Ringer's Solutions .................. 67

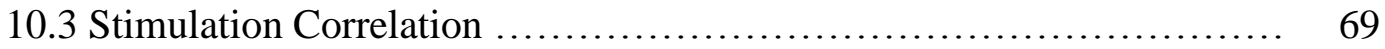

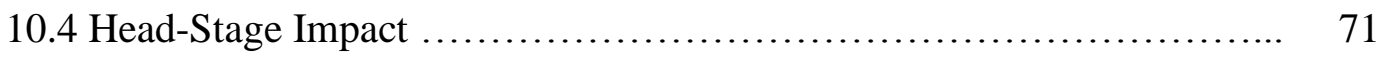

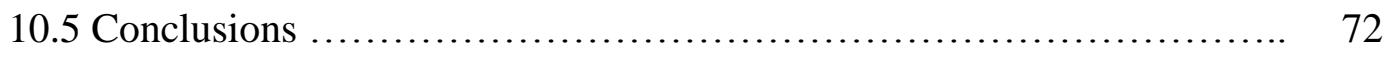

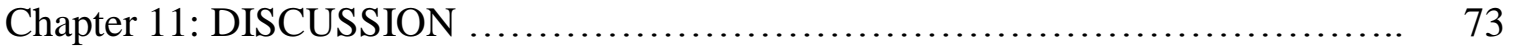

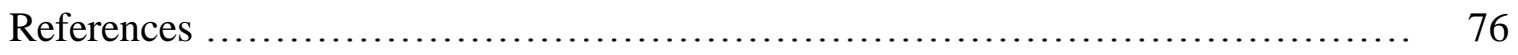




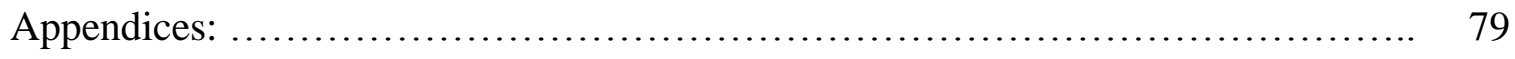

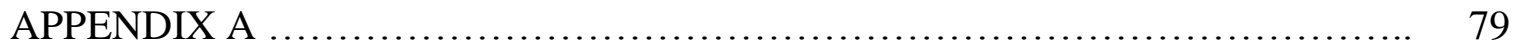

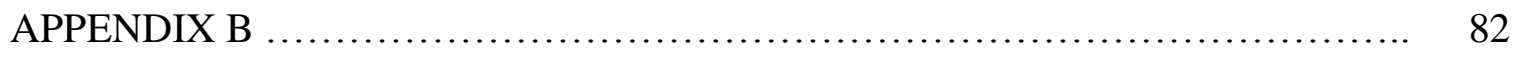

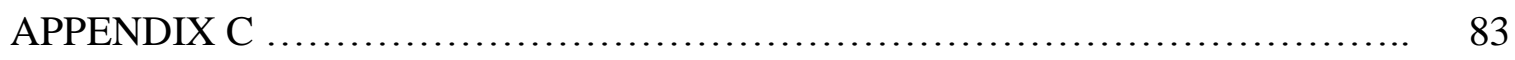

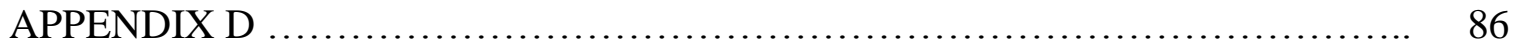




\section{LIST OF TABLES}

Table Page

Table 4-1 Intracellular and extracellular ionic compositions for a typical mammalian

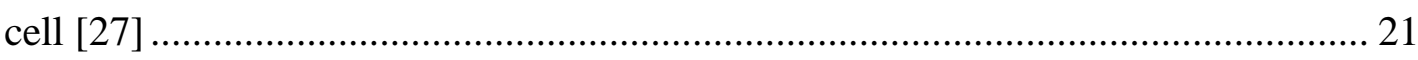

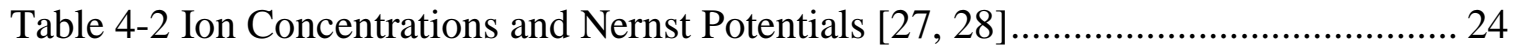

Table 7-1 Stock solutions available at Cal Poly Electrophysiology Lab and Ringer's

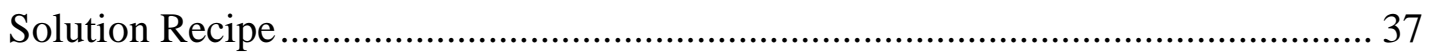

Table 7-2 Volumes of ingredients needed from stock to make Ringer's solution............ 38

Table 9-1 Typical timeframe from leech dissection to apparent cell death ..................... 55 


\section{LIST OF FIGURES}

Figure $\quad$ Page

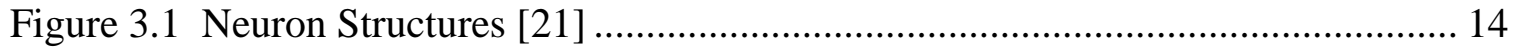

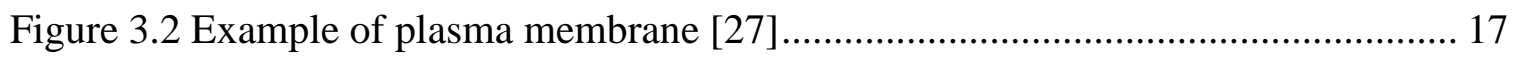

Figure 3.3 Examples of ion transporters and ion channels [28] f............................... 18

Figure 5.1 Cycle that leads to the depolarization of the plasma membrane [27]............ 27

Figure 5.2 Schematic showing the behavior of a single voltage-sensitive sodium channel

Figure 5.3 Schematic showing the behavior of a single voltage-sensitive potassium channel [27]

Figure 5.4 Schematic of phases of an action potential [30] ....................................... 29

Figure 6.1 Overview of cellular respiration and ATP production count [31] ................. 33

Figure 8.1 Anatomy of medicinal leech. A. Diagram of external body with outline of CNS positioning B. Cut-away diagram of mid-boy segment showing muscles and

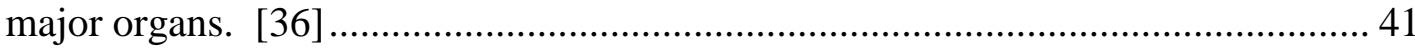

Figure 8.2 Mid-body ganglion anatomy. A. Ventral aspect. B. Dorsal aspect. [36] ....... 42

Figure 8.3 Example of leech pin-out and zoom-in of CNS .................................... 46

Figure 8.4 Example of ganglion positioning and micro-pin orientations ...................... 48

Figure 8.5 Final set-up having considered head stage and pipette entrance direction...... 50

Figure 9.1 Circuit diagram of voltage clamp technique [37] .................................... 52

Figure 9.2 Conceptual representation of voltage clamp technique [27] ......................... 53 


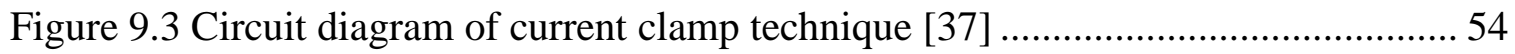

Figure 9.4 Conceptual representation of equipment set-up ..................................... 57

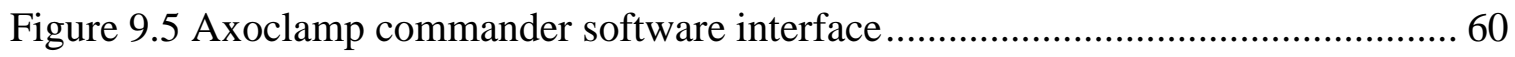

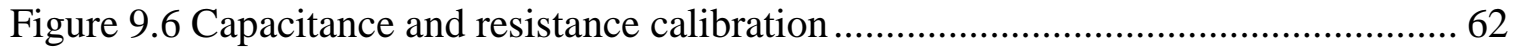

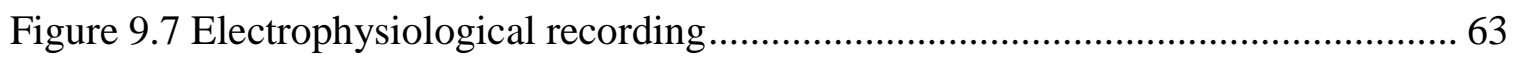

Figure 10.1 Clampex software action potential recordings A. Early in experiment B.

Later in Experiment

Figure 10.2 Bar graph showing the mean survival times of Retzius cell submerged in regular Ringer's solution versus glucose Ringer's solution. * indicates P-value $<.05$ with mean difference equal to 0 .

Figure 10.3 Scatter plot comparing regular Ringer's solution and glucose Ringer's solution to number of stimulations 71

Figure 11.1 Image of leech carcass with blue line indicating cutting points for disposal of leech 82

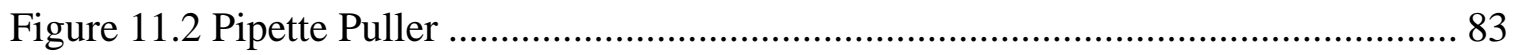

Figure 11.3 Image of glass pipette pushed towards the left and secured by both knobs .. 84 Figure 11.4 A. Pulled pipette B. Pipette tips stored 85 


\section{LIST OF VARIABLES}

\begin{tabular}{|l|r|}
\hline$E_{x}$ & Equilibrium potential $(\mathrm{mV})$ for ion $\mathrm{x}$ \\
\hline $\mathrm{R}$ & Ideal gas constant $=8.3145 \frac{\mathrm{J}}{\mathrm{mol} * T}$ \\
\hline $\mathrm{T}$ & Temperature $(\mathrm{K})$ \\
\hline $\mathrm{Z}$ & Valence of ion $\mathrm{x}$ \\
\hline $\mathrm{F}$ & Faraday's Constant $=9.6485 \mathrm{e} 4 \frac{\mathrm{c}}{\mathrm{mol}}$ \\
\hline$[\mathrm{x}]_{\text {in }}$ & Extracellular concentration of ion $\mathrm{x}$ \\
\hline$[\mathrm{x}]_{\text {out }}$ & Intracellular concentration of ion $\mathrm{x}$ \\
\hline $\mathrm{E}_{\mathrm{m}}$ & Membrane potential $(\mathrm{V})$ \\
\hline $\mathrm{P}_{\mathrm{x}}$ & Permeability of ion $\mathrm{x}(\mathrm{m} / \mathrm{s})$ \\
\hline
\end{tabular}




\section{CHAPTER 1：INTRODUCTION}

It is often the case in research that an experiment will require the investigation of an organic organism outside of its natural environment. With such requirements, the ability to artificially recreate various environments is a very important and crucial step in the progress of such research. This concept is valid for a wide range of environments ranging from physical habitats to biological settings. For example, behavioral studies using animals such as rats, mice, monkeys, or even humans, may require an experimental set-up that mimics what the natural environment would be for that subject. This allows the results of an experiment to be attributed to a specific variable rather than the results being due to an abnormal testing environment. Even more critical, perhaps, is the recreation of an environment used for testing organisms that cannot survive outside their natural setting. This is often the case when investigating microbiological organisms in vitro. Regardless of environment type, artificial recreation of a subject's surroundings is a very important aspect of research.

A perfect example of a microbial organism requiring an artificial environment is Legionella, the bacterium that causes Legionnaires' Disease. For years following the first documented outbreak of this disease in 1965, thousands of deaths were documented per year [1]. It was clear something was causing this sickness, but what organism was responsible proved tragically difficult to discover. It was not until January of 1977, over a decade later, that officials at the Center of Disease Control (CDC) 
announced that they had found the pathogen causing Legionnaires' Disease. After years of investigation, this pathogen was found to be a bacterium. Discovery of the bacterium required isolation in guinea pigs from autopsy specimens and propagation was performed in embryonated hens' eggs. [2] Nothing less than perfect combinations of several organisms were necessary for this bacterium to grow and be studied. Now called Legionnaires' disease bacterium (LDB), the cultivation of this bacterium requires an artificial growth environment, that if not available, the bacterium does not grow.

In this thesis, artificial solutions are used to support packets of neuronal cells outside of their host bodies. Similar to how a bacteria has requirements for growth, neuronal cells have their own set of requirements for communication and survival. Without an appropriate support solution, experiments on cells outside their host bodies would be impossible. Motivation for this project was established by curiosity in an optimal solution that can increase cell longevity compared to the currently used solution. To perform this experiment, packets of cells, called ganglia, were dissected from medicinal leeches and submerged in a glucose-enriched Ringer's solution and results compared to the already established Ringer's that does not contain glucose. It was of interest to test if a glucose-enriched Ringer's solution would extend cell longevity when compared to original Ringer's solution. Thirty minutes was arbitrarily chosen as the desired amount of time that would allow for changes to an experimental paradigm. 


\section{CHAPTER 2: RINGER'S SOLUTION}

There have been several solutions created for studying physiological states. This section summarizes the research of Sydney Ringer, whose name and discoveries are still used in labs today. Additionally, this section discusses some of the alterations to Ringer's solution and how these solutions are used today.

\subsection{Sydney Ringer}

Development of artificial environments was investigated by the physiologist, Sydney Ringer. Born in Norwich, England in 1835, Ringer came from a family of successful salesmen; Ringer's interest, however, was in medicine. In 1854, following a brief apprenticeship with a local medical practitioner, Ringer went to the University College in London. In 1860, Ringer qualified for his Bachelors of Medicine (MB) and only three years later received his Doctorate of Medicine (MD) and became a member of

the Royal College of Physicians where he became an assistant physician at the University College Hospital. In 1887, Ringer became a professor of medicine, a position he retained until his retirement in 1900. Ringer was an impressive worker and was inspired by many researchers working in anatomy and physiology. During this time, when the standard research tools of today were just being developed, research ideas and opportunities were flourishing and the possibilities expanding. One such influential invention was that of Carl Ludwig's, a Professor of Physiology at Marburg, Zurich, Vienna and Leipzig. In 1847, Ludwig designed the kymograph, or wave writer, which utilized a mercury filled manometer, a revolving drum and a stylus to simultaneously record changes in blood 
pressure and air pressure in a thoracic cavity. With this device, pharmacologists were able to run experiments measuring changes in physiological function due to the administration of drugs. Additionally, Ludwig's second major contribution to the world of research was his method of supporting an isolated organ by perfusing it in an oxygenated nutrient solution. Techniques such as these proved, years later, to be of great inspiration and use in Ringer's investigations including those on blood clotting, muscle contraction, and conduction of peripheral nerve impulses. [3-5]

It was in 1882 when Ringer began his studies on organic constituents of blood to see their influence on the contraction of the heart. His ultimate goal was to create an artificial circulating fluid that would maintain a contracting heart. Ringer used frogs as his animal model. Contrary to the four-chamber mammalian heart, the frog heart contains three chambers: two atria and a single super-fused ventricle that contains two narrow chambers to prevent mixing of oxygenated and deoxygenated blood. Additionally, the frog heart contains no coronary vascular supply which allows for cleaner dissections. Most importantly, however, is the availability of monocyte extracellular space inside the ventricular lumen that allows for easy and rapid ionic exchange with the extracellular fluid. Furthermore, the frog heart has a slow contraction rate at room temperature, which is especially useful for more accurate recordings using a kymograph and when visual observation acts as the main source of evidence for research, as it did for most of Ringer's findings. [6] 
Ringer first experimented with two circulating fluids: a saline solution and a blood mixture. His saline solution was "ordinary 0.75 percent solution of sodium chloride." The blood mixture contained one part dried bullock's blood to five parts saline solution. Ringer used 100 cubic centimeters, or 100 milliliters, of either solution in each experiment. To circulate the fluid through the frog's heart and body, Ringer inserted a double cannulation tube through the atria and into the ventricle, tying the tube down as close as possible to the auriculo-ventricular groove. Measurements were made using "Roy's tonometer," a device designed to measure transmission of volume using a closed vessel and a lever to report the movement of volume via an oil reservoir. In this case, the changes recorded were that of ventricular volume. [7]

Ringer ran several experiments circulating the blood mixture and the saline solution through the frog heart. His findings showed that circulating the saline solution caused a prolonged dilation, or enlargement, of the ventricle. During dilation, blood enters the ventricle for expulsion to the rest of the body; when dilation is prolonged, blood is not getting delivered to the body as often and as naturally as it should. To further test the effects saline was having on the ventricle, Ringer tried a stronger saline solution, 1.5 percent, and found the same results with an earlier occurrence than with the 0.75 percent saline. He also found that circulating the blood mixture after the saline solution would return the heart to a normal contraction, reversing the changes seen with saline solution. Ringer questioned how the blood mixture, being mixed with saline solution and thus containing an excess of soda salts, did not also cause the prolonged ventricular 
dilation. Ringer found that after about sixty minutes of circulating the saline solution, contractions of the ventricle would become very weak and the dilations were still prolonged. Within a short time of substituting the blood mixture for the saline, however, the contraction would grow stronger and the dilation would become quicker. After forty minutes, the contractions were almost as good as at the beginning of the experiment. It was clear that some constituent of blood in the blood mixture was eliminating the prolonged dilation cause by the saline solution alone. [7]

To investigate which constituent of blood was eliminating the prolonged dilation of the ventricle, Ringer introduced albumins and potassium chloride in the form of an egg white solution to the circulating saline solution. The egg white solution, consisting of one part egg white to two parts water, was added after the saline solution expectedly initiated prolonged dilation. It took only two minutes for the heart contractions to return to the state they were in when the heart was supplied with the blood mixture. Ringer's following experiments tested which constituent of the egg mixture removed the prolonged dilation. By experimenting with both albumin and potassium chloride individually with the saline solution, Ringer found that even minute traces of potassium chloride in the saline solution would eradicate the prolongation of dilation seen with saline solution alone. Experiments with albumin alone did not produce the same results. Ringer's final experiments using a potassium chloride infused saline solution were able to keep the heart beating for over four hours with contractions consistent with the beginning of the experiment when the heart was supplied the blood mixture. Ringer was ultimately 
able to conclude that a solution consisting of one cubic centimeter (one milliliter) of one percent potassium chloride solution in one hundred cubic centimeters (one hundred milliliters) of circulating saline made an excellent artificial circulating fluid for the heart. [7]

It was not long after the publication of his findings, however, that Ringer discovered an error in his experiments that would greatly alter his conclusions. The saline solution Ringer had used in his previous experiments had not been prepared with distilled water, but rather with pipe water supplied by the New River Water Company. It was implied in Ringer's obituary several years later, that his lab technician had had a hard time keeping up with Ringer's demands for the lab. Under normal circumstances, the error of using tap water rather than distilled water could lead to many complications; however, in this case, it may have paved the path for Ringer's future findings. He continued his research as follows:

"...As this water contains minute traces of various inorganic substances, I at once tested the action of saline solution made with distilled water and I found that I did not get the effects described in the paper referred to. It is obvious therefore that the effects I had obtained are due to some of the inorganic constituents of the pipe water." [8]

Ringer's analysis of the tap water revealed that it contained 278.6 parts of solid per million. This included "the presence of sodium, magnesium, potassium, carbonic and sulfuric acids, chloride and silicates". [9] Perhaps most significant, however, was the 
presence of calcium at 38.9 parts per million. Ringer's subsequent paper, in 1883, investigated the influence of calcium and sodium salts added to saline solution on the action of the contraction of the ventricle.

To continue and to correct his research, Ringer repeated his previous experiments with refined and new solutions. The saline solution contained 0.75 percent sodium chloride and was now prepared with distilled water. The calcium chloride solution was prepared with one part calcium chloride in 390 parts distilled water. Lastly, the potassium chloride solution used was a one percent potassium chloride solution. Using these solutions, Ringer found that circulating the calcium chloride solution produced the same changes in the ventricular beat that he had observed in his previous experiments: the ventricle contraction weakened and the diastolic dilation was prolonged. Ringer also found that with the addition of even minute traces of potassium salt, the effects of the calcium chloride solution on the ventricle were completely removed. Therefore, although calcium salts are necessary for proper contraction of the heart, potassium salts are required in correct proportion to the calcium salts to antagonize the effects of calcium and allow for relaxation of the heart muscle. [8] The solution formulated through all his experiments is now known as Ringer's Solution.

Ringer's solution was made to replace blood and provide a medium in which organisms can function and be studied outside of their natural environments. Ringer was ahead of his time, and it was not until about twenty years later, with the knowledge of 
diffusion and the disassociation of ions becoming a part of biological thinking, that Ringer's solution really caught scientist's attention. [5]

\subsection{Modifications to Ringer's Solution}

\subsubsection{Frank S. Locke}

Since the time of Ringer's studies, many scientists have made contributions and alterations to the established Ringer's solution to fit their experimental needs. Frank S. Locke, an English physiologist born in 1871, followed closely behind Ringer and in 1895 studied the effects of different sources of tap water on the maintenance of physiological features; in his case, the contractility of the grass-frog Sartorius muscle. [10] Since tap water sources varied, Locke investigated these waters after their distillation and found that minute traces of various heavy metals were shown to have been dissolved in them. These metals rendered the water "poisonous" and when placed in glass storage containers, it would stain the glass with its poisons. It was found necessary to distill the water with the glass apparatus for some days to remove the poisonous residue from the glass. From his experiments, Locke was able to conclude that certain crystalloids can be added to the water to prevent the fatal actions of traces of heavy metals, in his case, on the survival of tadpoles and tubifex fish. [10] In another study, Locke found that the addition of dextrose to a suitable inorganic solution kept a frog heart working for over 24 hours, much longer than Ringer's experiments, which lasted two to five hours. [11] 


\subsubsection{Maurice Vejux Tyrode}

Maurice Vejux Tyrode, an American physiologist and author of a pharmacological textbook summarizing the effects of several different drugs on physiological systems [12], altered the Ringer-Locke's solution to contain magnesium, bicarbonate, and large proportions of phosphoric acid and is often gassed with carbon dioxide. Like the Ringer-Locke solution, Tyrode's solution also contains glucose. [13] Today, Tyrode's solution is used for several types of physiological experiments and cell culture applications.

\subsubsection{Alexis F. Hartmann}

Intravenous saline solutions date back to Ringer's time when Thomas Latta, who during the cholera epidemic in 1831-1832, pioneered its use for the treatment of cholera. [14-17] Almost a century later, Alexis F. Hartmann and Dan C. Darrow, both American pediatricians, published a series of papers studying the chemical changes that occur in the body as a result of certain diseases and their suggested solution to remedy those toxic changes. [18-20] Their investigations on the composition of plasma found disturbances in acid-base balance, due primarily to the loss of bicarbonate from the plasma. Through their studies, they concluded that proper administration of an alkali, such as sodium bicarbonate, along with correct concentrations of a salt solution, such as Ringer's Solution, could provide rapid relief from acidosis. [20]

In 1929, Hartmann, in collaboration with Robert Elman, published further research on the treatment of acidosis. In their paper, they present the several setbacks of 
bicarbonate as a remedy for acid-base disturbances and a solution to these setbacks. [21] First off, for proper dosage measurements of bicarbonate, chemical examinations of blood were necessary, an important disadvantage when dealing with emergency situations. Additionally, to eliminate the irritability of subcutaneous or intraperitoneal administration of a bicarbonate solution, it was necessary to sterilize the solution through a filtration process and adjust the $\mathrm{pH}$ to 7.4 by means of the addition of carbon dioxide, which, if not sealed, would once again become alkaline with the eventual loss of $\mathrm{CO}_{2}$. Even more, if administered intravenously, bicarbonate produced too rapid of a change in the reaction of body fluids and often resulted in a shift from acidosis to alkalosis. [22] Hartmann and Elman suggested a new solution containing an abundance of a fixed base, such as Sodium lactate, over the use of the fixed acid, bicarbonate. [21] The conversion of sodium lactate into sodium bicarbonate provided sufficient time for both the treatment of acidosis with less danger of alkalosis. Furthermore, sodium lactate, both alone or combined with Ringer's Solution is non-irritating and can be sterilized simply by boiling. [22] Hartmann later used this lactated Ringer's solution in a series of studies with Milton J. E. Senn [22-24] to study the metabolism of sodium lactate and combat metabolic acidosis in his young patients. Lactated Ringer's solution is also known today as Hartmann's solution.

\subsection{Ringer's Solution Today}

Today, Ringer's solution and its many alterations still play an active role in medicine and research. Hartmanns's solution and solutions like it are used in medicine 
for fluid replacement for a variety of medical conditions. Ringer's solution also continues to serve its purpose in research to study organisms outside of their host environments by providing the necessary electrolyte balance and recourses for survival of the organism. In this project, Ringer's solution was used to support ganglions outside of their host for the purpose of performing electrophysiological measurements. The addition of glucose Ringer's solution is not uncommon, however no formal study has been done to demonstrate the affect a glucose-enriched Ringer's solution would have on the longevity of a leech cell. 


\section{CHAPTER 3: THE NEURON}

To study survival of cells outside the normal environment that supports them, it is necessary to understand how the cell survives in its natural environment. In this thesis, neuronal cells were used which are excitable cells that receive, transmit, and analyze environmental information to coordinate an appropriate response. The anatomy of the neuron is reviewed in this section and information is provided for understanding later sections that describe cell survival.

\subsection{The Nervous System}

The nervous system is a complex system comprised of excitable cells and tissues that provide three general functions: sensory feedback, motor control, and linking of the sensory and motor systems. These functions are divided by the nervous system in two parts: The central nervous system (CNS) and the peripheral nervous system (PNS). The CNS consists of the brain and the spinal cord and acts as a command station by processing sensory inputs and sending out response signals. The PNS consists of the nerves that leave the CNS and travel to certain areas of the body and is responsible for receiving sensory input, transmitting it to the CNS, and then relaying CNS commands back to the body. Proper functioning of these systems is crucial for survival of the organism. Communication that enables the proper functioning of the nervous system as a whole is made possible by specialized, excitable cells called neurons. 


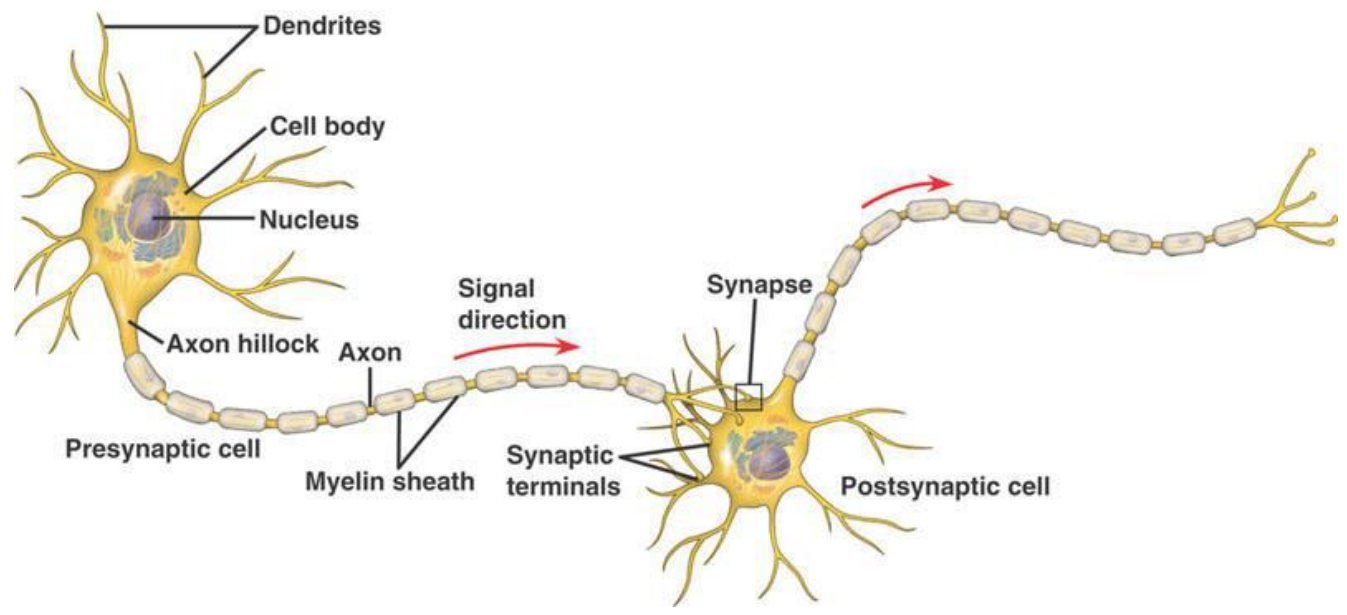

Figure 3.1 Neuron Structures [21]

\subsection{Neuron Structure}

The neuron is the main signaling unit of the nervous system. A typical neuron consists of four morphologically designed regions: the cell body, dendrites, the axon, and presynaptic terminals. Figure 3.1 depicts these regions. Each region has a distinct function in the generation of signals and in communicating those signals to other cells.

\subsubsection{The Cell Body}

The cell body, or the soma, is the brain of the neuron. The soma is where cell genes are stored and proteins are synthesized. Like most other cells, the soma contains specialized organelles responsible for protein and energy production, along with other important activities. It is in the organelle called the mitochondria where the neuron's supply of energy is created in the form of adenosine triphosphate (ATP). Sprouting from the cell body are two different types of processes: multiple dendrites and one axon. 


\subsubsection{Dendrites}

Dendrites are responsible for receiving incoming signals from other cells. Neurons can have many dendrites, which branch many times, and are covered in dendritic spines where inputs from other cells are received. The signal received is processed and in response can generate action potentials that propagated away from the cell body by a long process called the axon.

\subsubsection{The Axon}

The axon is the main conducting unit of the neuron capable of propagating signals along distances ranging from $0.1 \mathrm{~mm}$ to as long as 2 or $3 \mathrm{~m}$. [25] The axons of many neurons are wrapped in an insulating sheath of myelin composed of membranes of interstitial cells, Schwann cells outside the CNS and oligodendrocytes within the CNS. This insulating layer protects the axon and the propagating signal while increasing the speed of the signal. Signals are regenerated as they travel down the axon in regular intervals gaps in the myelin sheath called nodes of Ranvier. Near its end, the axon splits into smaller branches, each of which end in a swollen structure called the axon terminal.

\subsubsection{Axon Terminals}

Axon terminals serve as the communication site to other neurons. The cell transmitting the information is called the presynaptic cell, and thus, its axon terminals are referred to as presynaptic terminals. Cells receiving the information are consequently called postsynaptic cells, and their terminals, postsynaptic terminals. The point at which communication occurs between the two cells is called a synapse. 


\subsubsection{Synapses}

The small gap that separates the two communicating cells is called the synaptic cleft. In the synaptic cleft, chemical messengers are transferred from the presynaptic terminals to the postsynaptic terminals and thereby either stimulating or inhibiting the postsynaptic cell.

\subsection{Cellular Membrane}

The plasma membrane is the selectively permeable, outermost membrane of neurons and other tissue cells alike. The membrane separates intracellular and extracellular environments and regulates the passage and exchange of molecules and ions. Generally, $98 \%$ of the plasma membrane is composed of lipids, $75 \%$ of which are phospholipids. The phospholipids form a bilayer characterized by hydrophilic head groups pointing outwards and hydrophobic tails pointing inwards. See Figure 3.2. This formation renders the membrane impermeable for most water-soluble molecules and open for very small and polar molecules to diffuse through. [26] 


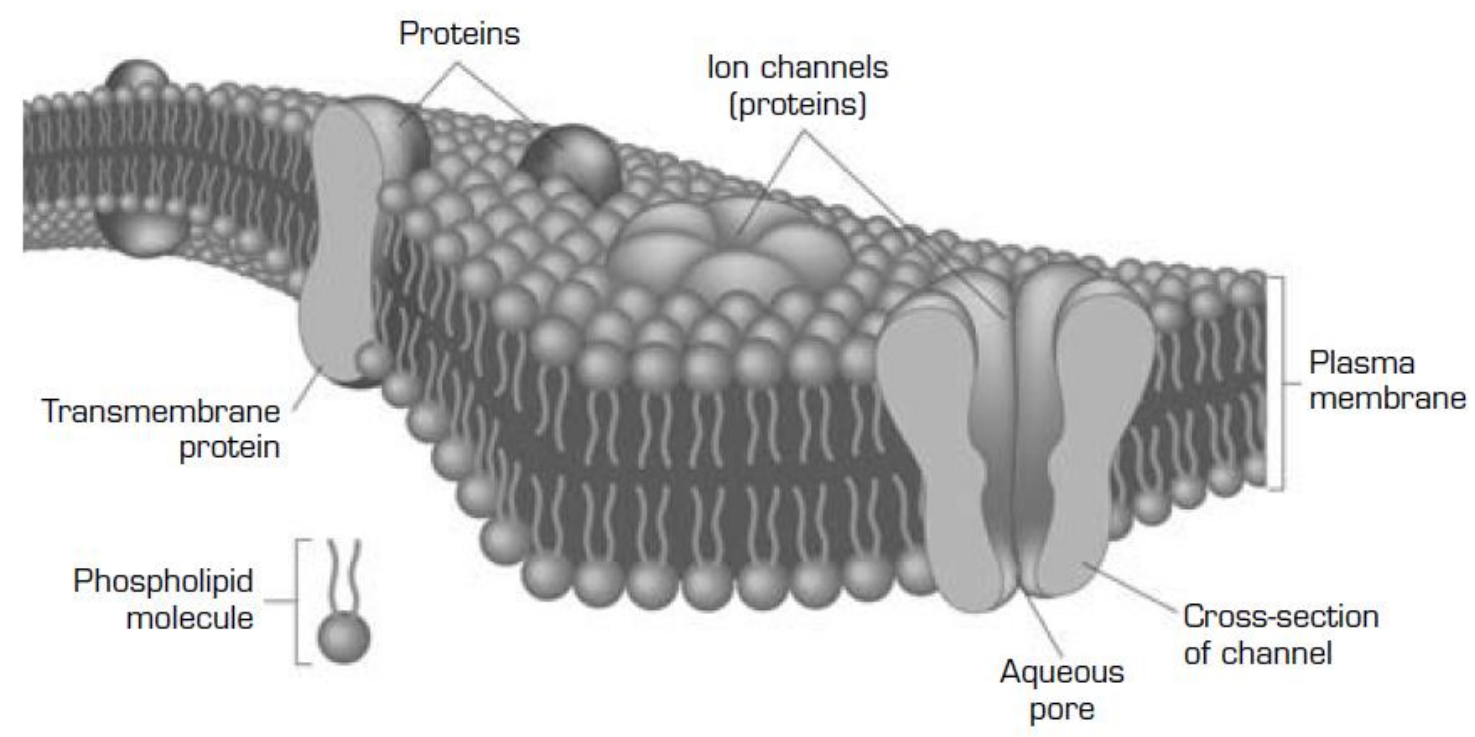

Figure 3.2 Example of plasma membrane [27]

The remaining $2 \%$ consists of diverse proteins embedded in the membrane that serve as channels for the passage of molecules from one side of the membrane to the other. These channels are often selectively permeable to specific substances and open and close in response to different stimuli. If molecules are to pass through the membrane, it will happen in one of two ways: simple diffusion or by means of a membrane protein. Membrane proteins include ion channels and transporters. See Figure 3.3 . 

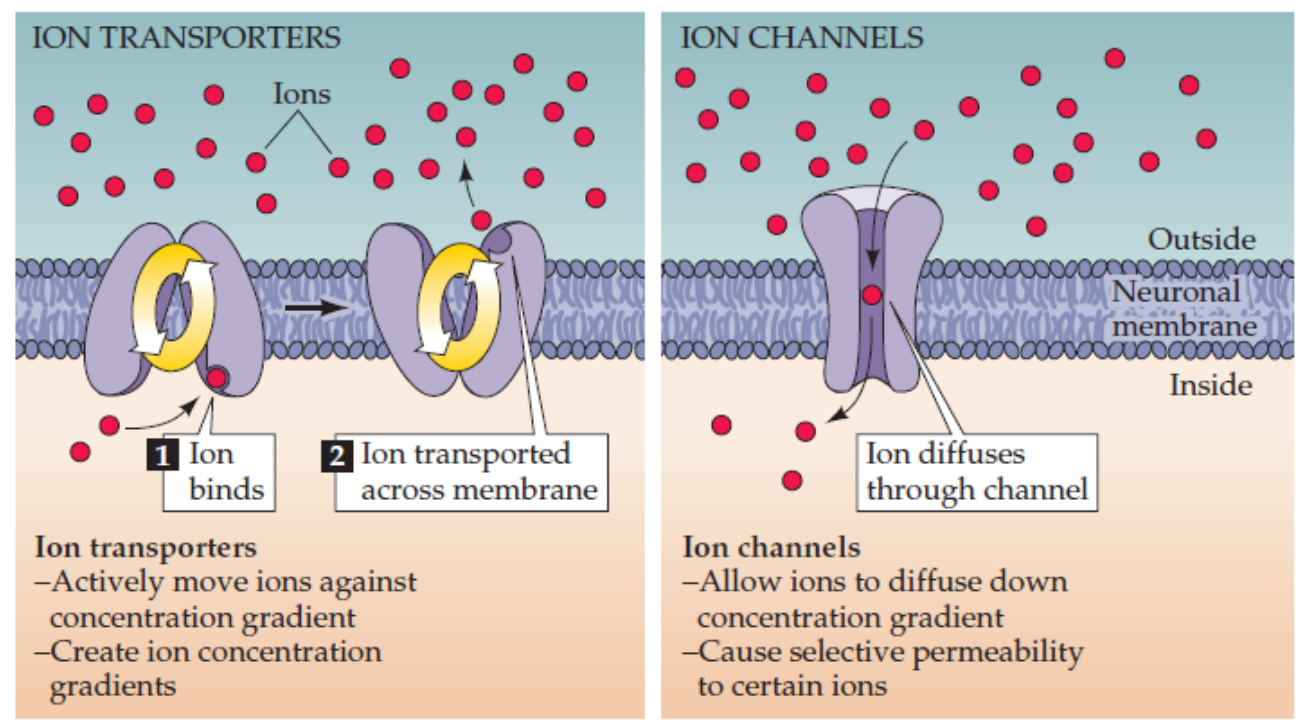

Figure 3.3 Examples of ion transporters and ion channels [28]

\subsubsection{Ion Channels}

Ion channels allow rapid membrane passage of an ion by means of facilitated diffusion. They are selectively permeable and alternate between an open and closed state. Some ion channels can be "gated" and require a stimuli to open. Such stimuli include changes in membrane potential or the binding of a neurotransmitter or ligand. Ion channels that are sensitive to changes in membrane potential are called voltage-gated ions and they are fundamental for neuronal excitability.

\subsubsection{Transporters}

Transporters, or carriers, actively bind molecules to transport them across the membrane. Transporters can move molecules in either direction across the cell membrane, in what is called passive or active transport. Passive transport moves molecules with their concentration or electrochemical gradient; Active transport is the 
movement of molecules against these gradients. The gradients are created due to differences in concentrations and electrical charges of ions inside and outside the cell. While passive transporters can "passively" transport molecules across the membrane, active transport requires energy derived by the hydrolysis of adenosine triphosphate (ATP) to push molecules against their "passive" or natural flow direction. The cellular membrane is what keeps intracellular and extracellular fluid compositions separated while active transporters maintain the intracellular and extracellular ionic concentrations. These differences in ionic concentrations inside and outside the cell generate an electrical field across the membrane called the membrane potential. 


\section{CHAPTER 4: MEMBRANE POTENTIAL}

Water is the most abundant molecule in the body, making up about 99 percent of all the molecules of the body. 0.25 percent can be attributed to proteins and nucleic acids. The final 0.75 percent, then, consists of simple inorganic substances, mainly sodium, potassium, and chloride ions. [27] It is a combination of water and these simple organic substances that make up the intracellular (ICF) and extracellular fluids (ECF) that keep nerve cells alive and capable of transmitting information from one cell to another. This section will detail the cellular membrane environment and resting state characteristics that set the stage for cellular excitability.

\subsection{Intracellular and Extracellular Environments}

As mentioned previously, fluids inside and outside the cell are different in composition and are kept separate by the cell's outermost membrane, the plasma membrane. Table 4-1 shows the simplified compositions of ICF and ECF, and whether or not the constituents can cross the plasma membrane. $\mathrm{A}^{-}$comprises all intracellular anions (negatively charged ions) which includes protein molecules, amino acids, and other inorganic ions.

Intracellular concentrations of cations are dominated by potassium, and contain much less sodium. Conversely, extracellular concentrations are dominated primarily by sodium, and much less potassium. Also important is whether or not a substance can cross the plasma membrane. The plasma membrane is permeable to potassium, chloride, and 
water, and less permeable to sodium. This difference in intracellular and extracellular concentrations plays an important role in the resting state of the cell.

Table 4-1 Intracellular and extracellular ionic compositions for a typical mammalian cell [27]

\begin{tabular}{lccc}
\hline & $\begin{array}{c}\text { Internal } \\
\text { concentration } \\
{[\mathbf{m M}]}\end{array}$ & $\begin{array}{c}\text { External } \\
\text { concentration } \\
{[\mathbf{m M}]}\end{array}$ & $\begin{array}{c}\text { Can it cross the } \\
\text { plasma } \\
\text { membrane? }\end{array}$ \\
\hline $\mathbf{K}^{+}$ & 125 & 5 & $\mathrm{Y}$ \\
$\mathbf{N a}^{+}$ & 12 & 120 & $\mathrm{~N}^{*}$ \\
$\mathbf{C l}^{-}$ & 5 & 125 & $\mathrm{Y}$ \\
$\mathbf{A}^{-}$ & 108 & 0 & $\mathrm{~N}$ \\
$\mathbf{H}_{\mathbf{2}} \mathbf{O}$ & 55,000 & 55,000 & $\mathrm{Y}$ \\
\hline
\end{tabular}

* Section 4.2 will show how this "no" is not exactly accurate

\subsection{Resting Membrane Potential}

\subsubsection{Electrochemical Gradient}

The electrochemical gradients are the gradients created due to differences in intracellular and extracellular ion concentrations and electric charges. Ion channels and transporters work in conjunction and maintain both the electric and chemical potentials. Chemical gradients are established by differences in concentrations of specific ions across the membrane. Ion channels then facilitate ionic diffusion of permeable ions in the direction of their chemical gradient. Electric gradients are established by the electrostatic forces ions exert on one another. Ions with like charges will repulse one another while 
ions with opposite charges will attract one another. Transporters allow movement of ions against these gradients. [26, 28]

Equilibrium potentials exist for each permeable ion. The electrochemical gradient is at an exact balance between the two opposing forces. At cellular rest, however, interacting electrochemical gradients of sodium and potassium ions and ion membrane permeability generate what is called the resting membrane potential. At rest, electrochemical gradients are not equal to zero; rather, movement of ions through open channels and down their electrochemical gradient still occurs and, in combination, create the resting membrane potential. [27]

\subsubsection{Sodium-Potassium Pump}

The sodium-potassium pump $\left(\mathrm{Na}^{+} / \mathrm{K}^{+}\right.$ATPase $)$is the active transporter essential in maintaining the membrane potential; it is an energy-dependent transporter that uses energy derived from the hydrolysis of ATP to actively transport sodium and potassium ions against their electrochemical gradient. As seen in Table 4-1, internal concentrations of ICF are dominated by potassium, while external concentrations are dominated by sodium. The sodium-potassium pump works by binding three sodium ions and one ATP at the intracellular face of the membrane and, using the cleaved energy of ATP hydrolysis, releases the sodium outside of the cell. The protein must then bind two potassium ions on the outer surface of the cell membrane to return to the configuration in which it can again bind sodium and ATP. [26, 27] 
Sodium-potassium pumps are necessary in restoring intracellular and extracellular concentrations of sodium and potassium that are lost to leak channels. Leak channels are present in nerve cells and passively allow sodium or potassium to flow down their concentration gradients. The cell membrane has many potassium leak channels which allow potassium to leave the cell. The sodium-potassium pump adjusts for this "leak" of potassium out of the cell and preserves a constant membrane potential. [29]

\subsubsection{Ion Permeability and Regulation}

Membrane potential is most influenced by sodium and potassium concentrations and permeabilities. At rest, the membrane potential reaches a point at which sodium influx is balanced by potassium efflux. Most cells experience a much higher permeability to potassium than sodium, and thus the balance rests closer to the equilibrium potential for potassium. To keep the resting membrane potential at a steady state, there is a constant exchange of intracellular potassium for sodium which is regulated by the sodium-potassium pump. $[27,28]$

\subsection{Theory}

\subsubsection{Nernst Equation}

The electrical potential generated across the membrane at electrochemical equilibrium, the equilibrium potential, can be calculated using the Nernst equation:

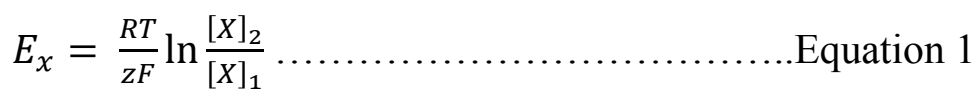


The Nernst equation calculates the equilibrium potential for one ion at a time and only to ions that can cross the barrier. [27] At equilibrium, net force driving an ion in crossing the barrier is zero; the Nernst equation relates the electrical potential and distribution of charged ions across the permeable membrane. [29] Below is a table showing ionic concentrations and associated Nernst potentials for a squid neuron and a mammalian neuron.

Table 4-2 Ion Concentrations and Nernst Potentials [27, 28]

\begin{tabular}{lccc}
\hline \multicolumn{1}{c}{ Ion } & $\begin{array}{c}\text { Internal } \\
{[\mathbf{m M}]}\end{array}$ & External [mM] & $\begin{array}{c}\text { Nernst Potential } \\
{[\mathbf{m V}]}\end{array}$ \\
\hline Squid Neuron & 400 & 20 & -75 \\
$\mathbf{K}^{+}$ & 50 & 440 & +55 \\
$\mathbf{N a}^{+}$ & 40 & 560 & -66 \\
$\mathbf{C l}^{-}$ & & & \\
$\mathbf{M a m m a l i a n}^{-}$ & & & -82 \\
$\mathbf{N e u r o n}^{+}$ & 125 & 5 & +59 \\
$\mathbf{K}^{+}$ & 12 & 120 & -82 \\
$\mathrm{Na}^{+}$ & 5 & 125 & \\
\hline $\mathbf{C l}^{-}$ & & & \\
\hline
\end{tabular}




\subsubsection{Goldmann Equation}

The Goldmann equation relates ion concentrations and permeabilities to calculate the membrane potential. This equation is similar to Nernst equation except that it takes into consideration the ions of sodium, potassium, and chloride:

$$
E m=\frac{R T}{F} \ln \left(\frac{P_{K}\left[\mathrm{~K}^{+}\right]_{o}+P_{N a}\left[\mathrm{Na}^{+}\right]_{o}+P_{\mathrm{Cl}}\left[\mathrm{Cl}^{-}\right]_{i}}{P_{K}\left[\mathrm{~K}^{+}\right]_{i}+P_{N a}\left[\mathrm{Na}^{+}\right]_{i}+P_{\mathrm{Cl}}\left[\mathrm{Cl}^{-}\right]_{o}}\right) \ldots \ldots \ldots \ldots \ldots \ldots \ldots \text { Equation } 2
$$

In most nerve cells, the effect of chloride on the resting membrane potential is insignificant and can be dropped from the Goldmann equation:

$$
E m=\frac{R T}{F} \ln \left(\frac{P_{K}\left[K^{+}\right]_{o}+P_{N a}\left[N a^{+}\right]_{o}}{P_{K}\left[K^{+}\right]_{i}+P_{N a}\left[N a^{+}\right]_{i}}\right) \ldots \ldots \ldots \ldots \ldots \ldots \ldots \text { Equation } 3
$$

Resting membrane potentials vary among different cells. For a mammal neuron, the Goldmann equation yields $E m=-71 \mathrm{mV}$. It is expected that the resting potential would lie closer to $E_{K}(-82 \mathrm{mV})$ than to $E_{N a}(+59 \mathrm{mV})$ due to the higher permeability to potassium. The Nernst and Goldmann equations are able provide valuable information about cell membrane permeability and intracellular and extracellular ionic concentration. $[27,28]$ 


\section{CHAPTER 5: THE ACTION POTENTIAL}

Neurons send and receive signals to other cells by means of electrical or chemical steps that are produced by modulating the membrane potential. The following section describes how these signals, called action potentials, are generated, propagate, and are passed from one cell to the next.

\subsection{Action Potential Overview}

An action potential is the signal that carries messages over long (and short) distances in the nervous system. These messages start at the origin of the axon, called the axon hillock, and are quickly propagated along the axon by means of all-or-none impulses. Action potentials are initiated by a transient, dramatic increase in sodium permeability causing a rise in the membrane potential and are normally triggered by some external stimulus.

\subsection{Permeability during an Action Potential}

\subsubsection{Voltage-Dependent Sodium Channels}

At cellular rest, membrane sodium channels are mostly closed and the resting potential lies closer to that of the potassium equilibrium value. When the membrane is depolarized due to external stimuli, voltage-dependent sodium channels are triggered to open, allowing sodium ions to carry positive charge into the cell, further depolarizing the membrane. Voltage-gated sodium channels and membrane depolarization form a positive feedback cycle causing a depolarization of the membrane. 


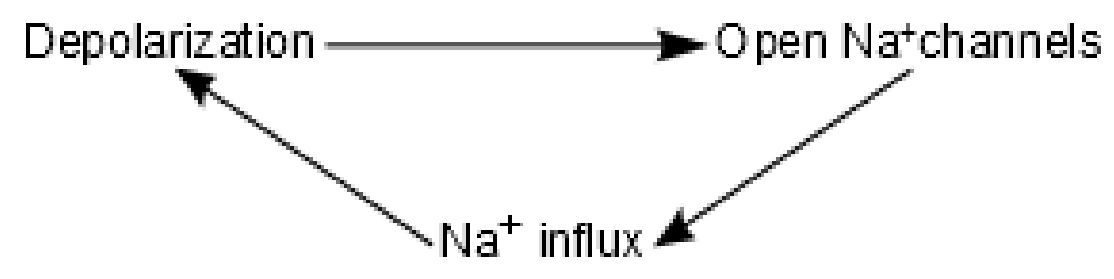

Figure 5.1 Cycle that leads to the depolarization of the plasma membrane [27]

This cycle is the start of an action potential and tends to continue until membrane potential reaches near to the value of the sodium equilibrium potential. This phenomenon also explains the all-or-none behavior of the action potential. Once triggered, the process tends to run to completion. [27]

For this cycle to start, however, membrane potential must reach a threshold. For moderate depolarization, potassium efflux may be larger than the influx of sodium and prevent the positive feedback cycle essential to the action potential. The membrane potential threshold reached must be at the point where the influx of sodium surpasses the efflux of potassium. This threshold value can vary for different neurons.

\subsubsection{Repolarization}

There are two factors that will restore the resting membrane potential of a cell: 1) the depolarization-induced increase in sodium permeability is transient, and 2) there is a delayed, voltage-dependent increase in potassium permeability. [27]

The transient nature of the voltage-gated sodium channels is seen in Figure 5.2. The sodium channel contains two gates, both of which respond to depolarization but with different speeds and in opposite directions. Image a) shows the $\mathrm{m}$ gate closed when the 
cell membrane is at resting value. At the same time, the $h$ gate remains open. Image $b$ ) depicts how the $\mathrm{m}$ gate opens in response to membrane depolarization and sodium is able to enter the cell. Meanwhile, the $\mathrm{h}$ gate begins to close, but at a slow rate. Image c) shows the h gate closed; this state is called sodium channel inactivation.
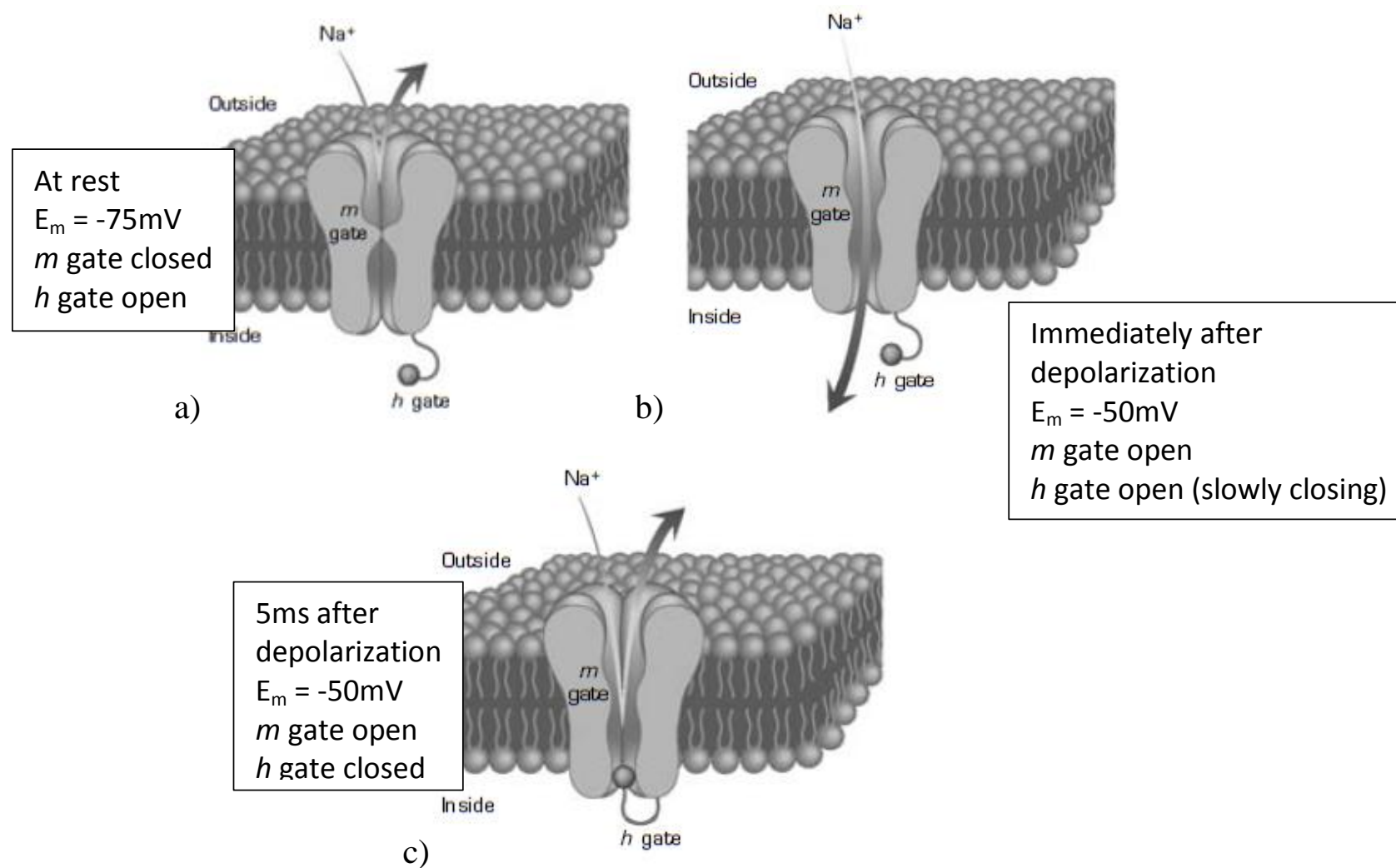

$h$ gate open (slowly closing)

Figure 5.2 Schematic showing the behavior of a single voltage-sensitive sodium channel [27]

Voltage-sensitive potassium channels consist of one gate called the $n$ gate. The $n$ gate is closed at membrane resting potential and opens slowly with depolarization. This allows for the efflux of potassium while the resting membrane potential returns to normal resting value. See Figure 5.3. 

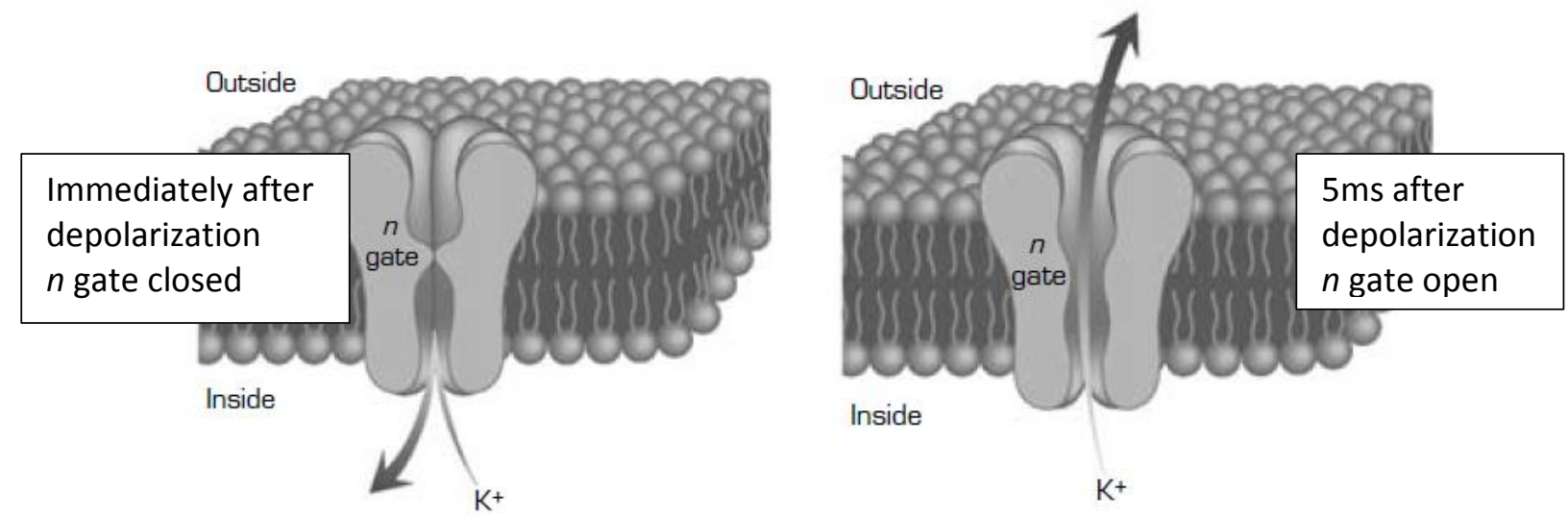

Figure 5.3 Schematic showing the behavior of a single voltage-sensitive potassium channel [27]

\subsection{Phases of an Action Potential}

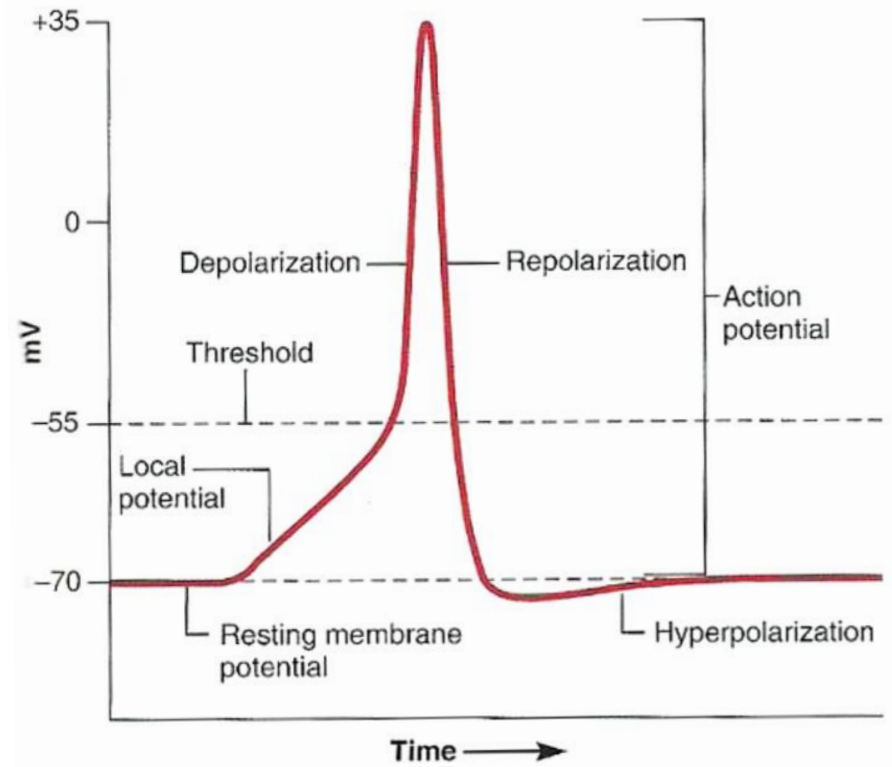

Figure 5.4 Schematic of phases of an action potential [30] 


\subsubsection{Resting Phase}

The resting phase of an action potential is when the cell membrane is at a steady state and capable of generating an action potential. For a typical mammalian cell, this is true at about $-71 \mathrm{mV}$, somewhere between the Nernst potential for potassium $(-82 \mathrm{mV})$ and the Nernst potential for sodium $(+59 \mathrm{mV})$, but closer to that of potassium. These values vary for different cell types. During the resting phase, the $\mathrm{m}$ and $\mathrm{n}$ gates are closed and the $\mathrm{h}$ gate is open. The resting membrane potential is kept constant by means of the sodium-potassium pump.

\subsubsection{Depolarization Phase}

The depolarization phase occurs when a stimulus of sufficient magnitude increases the membrane potential above its threshold value. When threshold is reached, $\mathrm{m}$ gates open, sodium rushes into the cell and the membrane potential rises to a value near that of the sodium equilibrium. During this phase, the h gate slowly closes and the $\mathrm{n}$ gate slowly opens in preparation for repolarization of the membrane.

\subsubsection{Repolarization Phase}

The repolarization phase begins once the membrane potential has reached its maximum. The slow-acting sodium channel h gate is closed and the potassium channel $\mathrm{n}$ gate is now fully open where potassium ions flow out of the cell until the membrane, once again, reaches resting potential. 


\subsubsection{Hyperpolarization Phase}

After repolarization, sodium $\mathrm{h}$ gates reopen allowing sodium levels to normalize while potassium $\mathrm{n}$ gates close slowly, allowing potassium to leave the cell. The extra efflux of potassium ions that occurs while the $n$ gates close decreases the membrane potential to below that of the resting value. This is called the hyperpolarization phase, or undershoot phase, of the action potential. 


\section{CHAPTER 6: CELLULAR RESPIRATION AND CELL SURVIVAL}

Cellular respiration is the process a cell takes to break down fuel and generate energy in the form of ATP. ATP is used for many cell functions including transport work, mechanical work, and chemical work. Mechanical work includes the supply of energy for muscle contraction. Chemical work includes the supply of energy needed to synthesize the many types of macromolecules cells need to exist. Transport work, as we are now familiar with, includes the supply of energy needed to move substrates across the cell membrane. [31] Perhaps most notable for this thesis is the need of ATP for the function of the sodium potassium pump. The sodium potassium pump maintains the resting membrane potential and is critical for survival and communication of nerve cells. This section will give a brief description on how eukaryotic cells synthesize ATP as well as an explanation of how this process was considered when developing ways to increase survival of cells in an in vitro condition. 


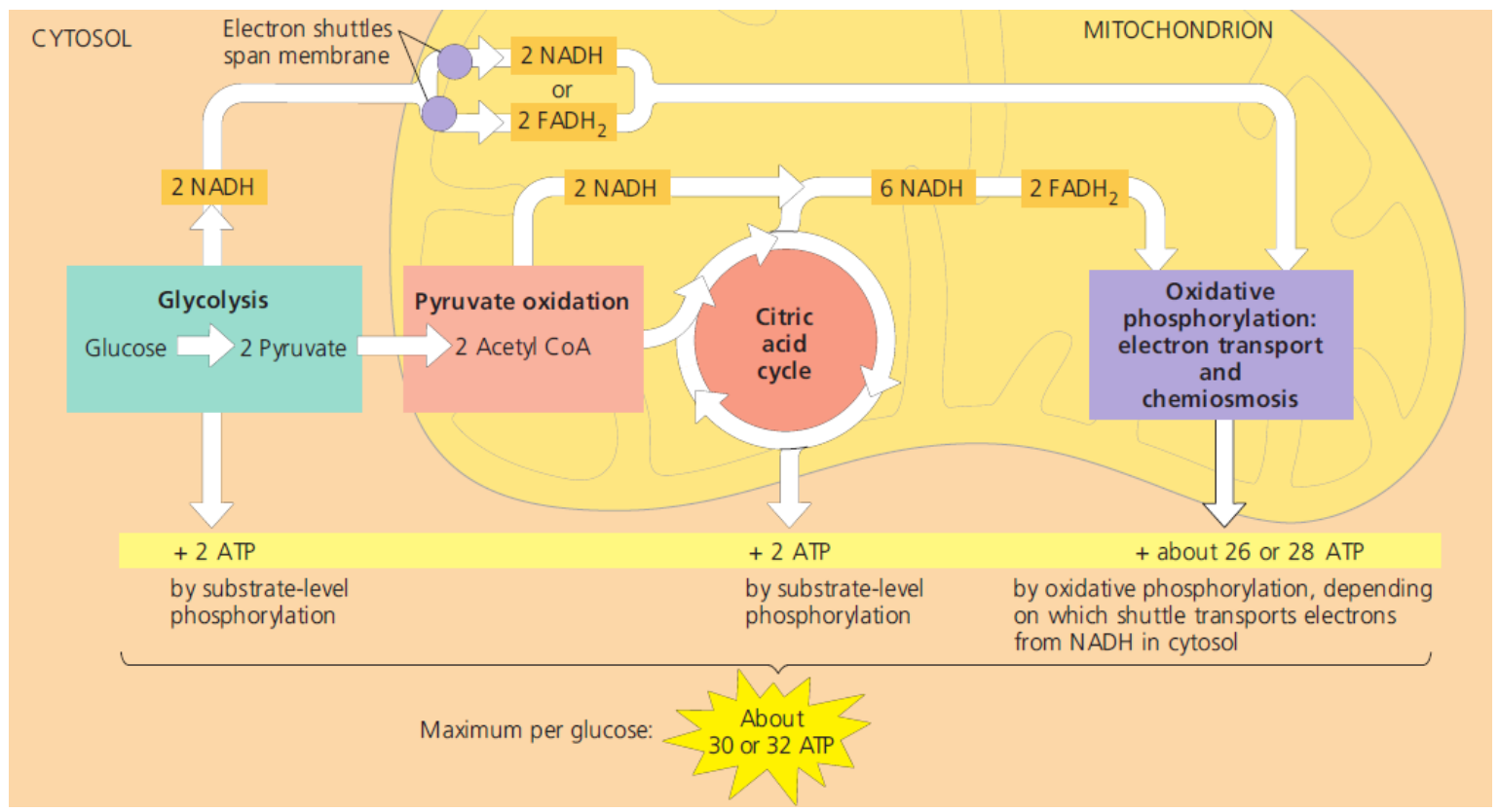

Figure 6.1 Overview of cellular respiration and ATP production count [31]

\subsection{Synthesis of ATP}

\subsubsection{Glycolysis}

Glycolysis actually means "sugar splitting." This process occurs in the cytosol of the cell and is the beginning of the breakdown of glucose. During this process, glucose, a six-carbon sugar, is converted into two molecules of the compound pyruvate. Although glycolysis requires energy to breakdown glucose, the net yield produces two ATP. This process releases less than a quarter of the chemical energy in glucose that can be used by cells. If molecular oxygen is present, the pyruvate molecules produced during glycolysis can enter the mitochondrion where cellular respiration is completed. [31] 


\subsubsection{Krebs cycle}

When pyruvate molecules enter the mitochondrion, they are first converted to a compound called acetyl coenzyme A, or acetyl CoA. Acetyl CoA then enters what is called the citric acid cycle, or Krebs cycle. The Krebs cycle consists of several steps that yield one ATP per cycle. This portion of cellular respiration produces two ATP, one for each Acetyl CoA that goes through the Krebs cycle. [31]

In addition to the ATP produced from glycolysis and the Krebs cycle, these processes also produce free hydrogen ions $\left(\mathrm{H}^{+}\right)$. NAD ${ }^{+}$(nicotinamide adenine dinucleotide) and FAD (flavin adenine dinucleotide), both well-suited electron carriers, form NADH and $\mathrm{FAHD}_{2}$, respectively, and carry $\mathrm{H}^{+}$ions to the third stage of cellular respiration, the electron transport chain. [31]

\subsubsection{Electron Transport Chain}

So far, only four ATP molecules have been produced via glycolysis and the Krebs cycle, two from each. Most of the energy extracted from glucose is actually stored in the $\mathrm{NADH}$ and $\mathrm{FADH}_{2}$ molecules. The $\mathrm{H}^{+}$ions being carried by these molecules are transferred to inner mitochondrion membrane proteins called cytochromes which pump the $\mathrm{H}^{+}$ions across the membrane into an intermembrane space. This creates a gradient of $\mathrm{H}^{+}$ions across the membrane referenced as the proton-motive force. This gradient then drives the $\mathrm{H}^{+}$ions down their gradient through membrane protein channels called ATP synthase, the enzyme that actually makes ATP from ADP. This process of energy stored in the form of an $\mathrm{H}^{+}$ion gradient across a membrane to drive ATP synthase is called 
chemiosmosis. The ATP synthase, the only channel for which $\mathrm{H}^{+}$ions can move down their concentration gradient, functions like an ion pump, but, in reverse, producing ATP from ADP and Pi. [31]

The electron transport chain can produce a maximum of 28 ATP form one glucose molecule. Adding ATP produced from glycolysis and the Krebs cycle, total ATP yield for one glucose molecule is 32 ATP. [31]

\subsection{Surviving Cells in vitro}

In the body, cells have access to the molecules used to generate energy, such as glucose, through the food consumed by the host. When cells are studied in vitro, they must depend solely on the artificial environment in order to stay alive. A solution to support neurons in vitro must, at minimum, contain the ions that exist in the intracellular and extracellular fluids of its natural environment $\left(\mathrm{Na}^{+}, \mathrm{K}^{+}, \mathrm{Cl}^{-}\right.$, etc. $)$. It is also crucial to mimic the $\mathrm{pH}$ of the cell's natural environment. Additional ingredients to the artificial environment can then be added, or substituted, to cater to individual experiments. Ringer's solution is a known solution for supporting cells outside their host body and a common starting point for artificial cellular environments. This solution contains the appropriate concentrations of ions that are isosmotic to the host cell and mimic the natural extracellular environment.

In this experiment, it was attempted to extend the longevity of action potential recruitment, and essentially survival, of a neuronal cell separated from its natural fuel 
resources. Although still inside the ganglion, these neurons are now dependent on the resources provided by an external fluid versus that provided by the host body, in this case, a leech. Neurons have very limited glucose storage and a shortage of glucose would be detrimental to the cell. Under normal metabolic conditions, cytoplasmic levels of ATP are $10 \mathrm{mmol} / \mathrm{L}$, which is essential for virtually all neuronal functions, $60 \%$ of which is used for the sodium potassium pump to maintain the resting membrane potential. [32] Because glucose is necessary for neurons to produce adequate amounts of ATP for survival, it was of interest to see if the addition of glucose to Ringer's solution would extend the life of neurons compared to the normal Ringer's solution. 


\section{CHAPTER 7: RINGER'S SOLUTION PREPARATIONS}

There have been several alterations to Ringers solution to cater to individual experiments. For the purpose of this experiment, two Ringer's solutions were prepared, one with glucose and one without. This section goes over the ingredients and preparations of both solutions.

\subsection{Regular Ringer's Solution}

Regular Ringer's solution contains the necessary ingredients to keep a cell alive for a certain amount of time when removed from its natural environment. The table below details the ingredients and concentrations of regular Ringer's solution as well as the concentrations of the stock solutions available in the Cal Poly Leech Electrophysiology lab.

Table 7-1 Stock solutions available at Cal Poly Electrophysiology Lab and Ringer's Solution Recipe

\begin{tabular}{lcc}
\hline & Stock Solutions (M) & Regular Ringer's (M) \\
\hline $\mathbf{N a C l}$ & 3 & .115 \\
$\mathbf{C a C l}_{2}$ & 1 & .0018 \\
$\mathbf{K C l}$ & 1 & .004 \\
Tris Maleate & 0.2 & .01 \\
\hline
\end{tabular}

To reach the desired regular Ringer's solution concentrations, it was necessary to calculate how much of each stock ingredient would be required, in this case, for a one 
liter solution. The table below shows the volumes required for the dilution of each ingredient to make one liter of Ringer's solution with the correct ingredient concentrations. Refer to appendix A for detailed calculations.

Table 7-2 Volumes of ingredients needed from stock to make Ringer's solution

\begin{tabular}{lllll}
\hline & NaCl $(\mathbf{m L})$ & $\mathbf{C a C l}(\mathbf{m L})$ & $\mathrm{KCl}(\mathbf{m L})$ & Tris Maleate $(\mathbf{m L})$ \\
\hline Regular Ringer's & 38.33 & 1.8 & 4 & 50 \\
\hline
\end{tabular}

All Ringers' solutions were prepared with distilled water. When preparing the solution, a small amount of distilled water was separated into a measuring cup and used to mix in other ingredients. After ingredients were pipetted in, the solution was topped off to about $900 \mathrm{ml}$. pH measurements were then taken and the solutions were titrated using either hydrochloric acid or sodium hydroxide, as needed, until the $\mathrm{pH}$ was 7.4. When the $\mathrm{pH}$ was stable at 7.4, the solution was topped off to one liter with distilled water and transferred over to a one liter, sealable glass container labeled with the type of solution (regular or glucose), the date, and the $\mathrm{pH}$. Ringer's solutions used for dissections were kept refrigerated at the same temperature as the leeches.

\subsection{Glucose Ringer's Solution}

Glucose Ringer's solution contains the same ingredients as the regular Ringer's solution described in the previous section with the addition of glucose. Other experiments have used glucose in their Ringer's solutions ranging from 10-13 mM 
concentrations. [33-35] For this experiment, a $13 \mathrm{mM}$ concentration was chosen for the glucose Ringer's solution.

To make a $13 \mathrm{mM}$ concentration glucose Ringer's solution, it was necessary to calculate how much glucose would be required to make, in this case, a one liter solution. Using the molecular weight of glucose (180.16 grams per mole), it was calculated that 2.34 grams of glucose in a one liter solution would make a solution with a $13 \mathrm{mM}$ concentration of glucose. Refer to appendix A for detailed calculations.

Glucose Ringer's solution was prepared using a liter of regular Ringer's solution made with distilled water. 2.34 grams of glucose was mixed into about half a liter of regular Ringer's solution. Once dissolved, regular Ringer's solution was added to about $900 \mathrm{~mL}$ and the solution was titrated using either hydrochloric acid or sodium hydroxide, as needed, until the $\mathrm{pH}$ was 7.4. When the $\mathrm{pH}$ stabilized at 7.4, the solution was topped off to one liter with the remaining Ringer's solution. Glucose Ringer's solution was stored in a one liter, sealable glass container labeled with the type of solution (regular or glucose), the date, and the $\mathrm{pH}$. Glucose Ringer's solution used for dissections was kept refrigerated at the same temperature as the leeches. 


\section{CHAPTER 8: HIRUDO MEDICINALIS AND DISSECTION PROTOCOL}

Neuronal electrophysiology research has greatly benefited from the study of invertebrate nervous systems. The simplicity of the nervous system in such animals has facilitated research in many areas of the nervous system. One such animal fundamental to this research is the medicinal leech, more specifically, Hirudo medicinalis. This section covers the anatomy and nervous system of the leech, necessary care instructions, and finally, a detailed protocol for the extraction of a mid-body ganglion of the Hiudo mediciniali. For this thesis, fifteen experiments were performed.

\subsection{Hirudo Medicinalis}

\subsubsection{Leech Anatomy}

Leeches are segmented worms, or annelids, with a fixed number of segments (32). These thirty-two segments are further divided into three sections based on location and function. The "head" consists of the four most anterior segments which are fused together to form the eyes and the mouth. The "tail" is also fused, consisting of the seven most posterior segments to form the large caudal sucker. Between the "head" and the "tail" are twenty one unfused, mid-body segments (M1-M21). Directly under the skin, the leech has three layers of muscle fibers. The outer layer is composed of circular muscle fibers, the inner layer of longitudinal muscle fibers, and the intermediate layer of two sheets of crossed oblique muscle fibers. Two other sets of muscle fibers may be found along the body of the leech, altogether permitting multidirectional contractions. [36] 
A.

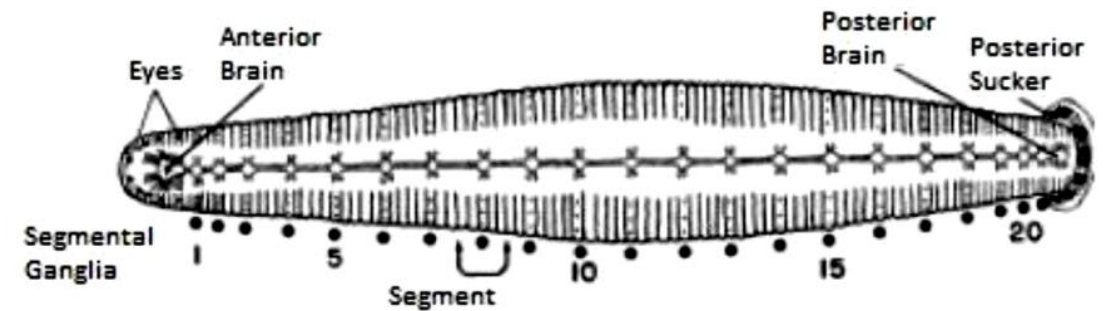

B.

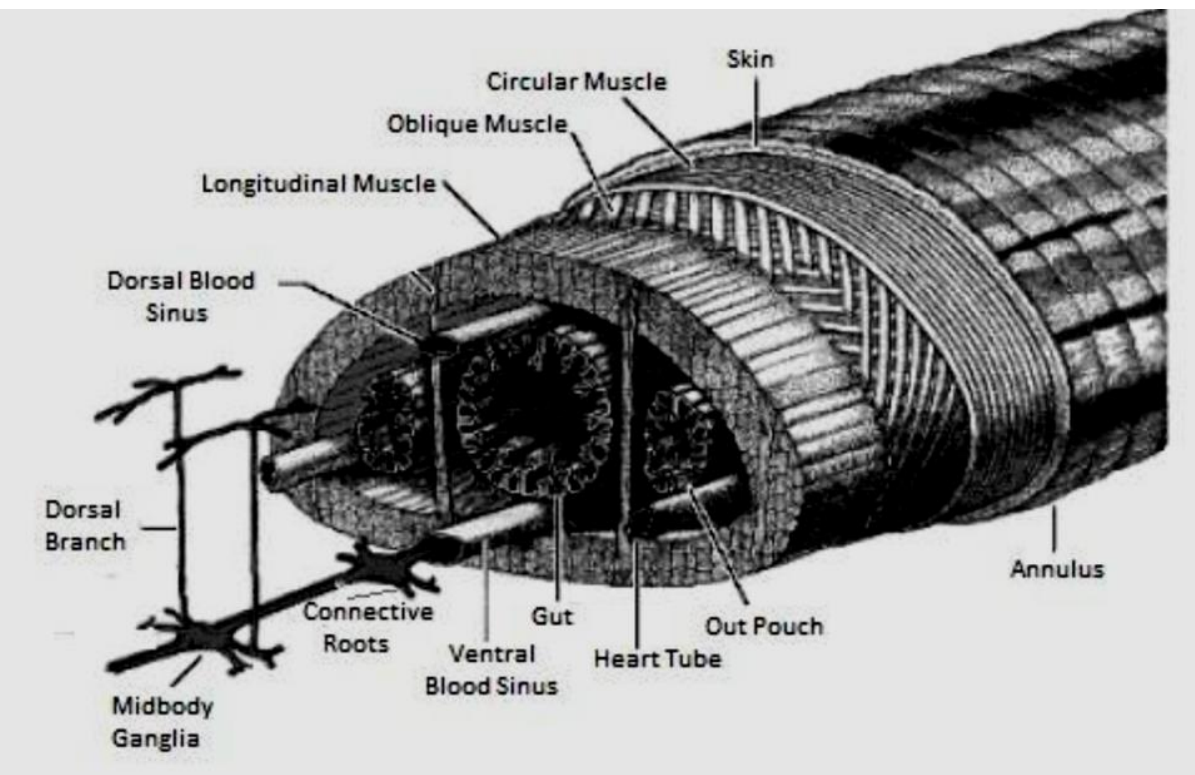

Figure 8.1 Anatomy of medicinal leech. A. Diagram of external body with outline of CNS

positioning B. Cut-away diagram of mid-boy segment showing muscles and major organs. [36]

\subsubsection{Leech Nervous System}

The leech nervous system reflects the segmental layout described above. Along the length of the leech is a ventral nerve cord with thirty-two segmentally associated ganglia. The four most anterior are fused together to form the anterior brain, and the seven most posterior are fused together to form the posterior brain. An unpaired, median connective called "Faivre's nerve" links the segmental ganglia to one another, while two 
paired connective roots branch out laterally from the ganglia and innervate the body wall musculature to anchor them. These connectives contain both interganglionic axons and longitudinal muscle fibers. [36]

Each segmental ganglion contains about 200 pairs of neurons and a few unpaired neurons. Different neurons are responsible for a diverse set of functions depending on the nerve type and location of the ganglia. Neurons from mid-body region ganglia have been most successfully mapped and categorized based on nerve function. The most effectively identified cell types include: the Retzius cell, the T cell, the P cell, and the $\mathrm{N}$ cell. [36]

A.

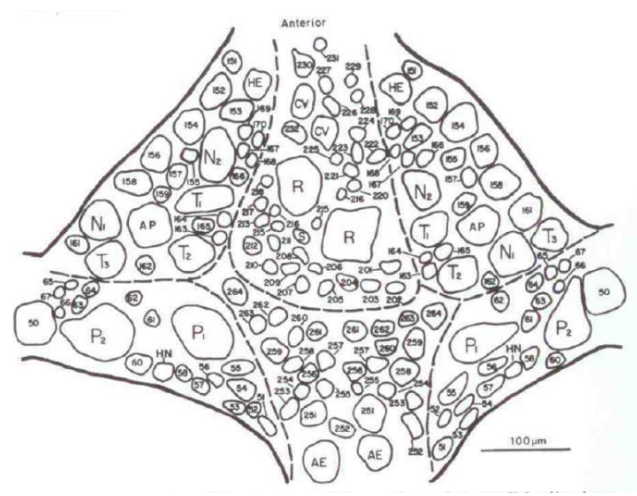

B.

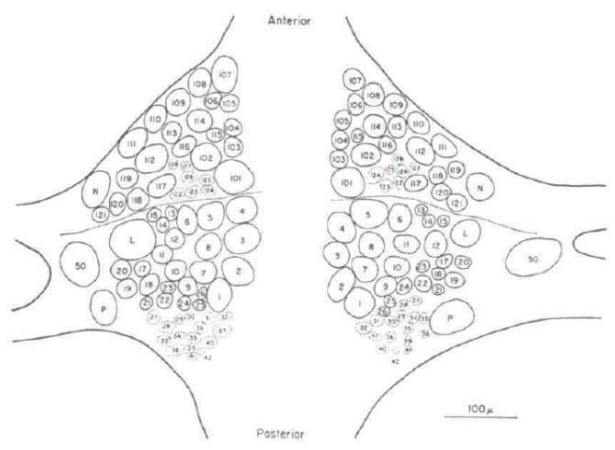

Figure 8.2 Mid-body ganglion anatomy. A. Ventral aspect. B. Dorsal aspect. [36]

The Retzius cells, or R cells, are the two large cells seen clearly in the center on the ventral aspect of the ganglia. . The R cells are effector cells that contain serotonin and are involved in mucus release, swimming, and relaxation of the longitudinal muscles. The $\mathrm{T}, \mathrm{P}$, and $\mathrm{N}$ cells are mechanosensory cells. The $\mathrm{T}$ cells are sensitive to touch, the $\mathrm{P}$ cells to pressure, and the $\mathrm{N}$ cells to noxious stimuli. [36] 


\subsubsection{Cell Selection}

Cell selection for this set of experiments was determined based on experimental reproducibility, cell identification, and cell accessibility to recording equipment. The Retzius cell is far superior with respect to these qualifications due to its size and location in the ganglia. Choosing the Retzius cell helped reduce variability in the experimental procedure.

\subsection{Leech Care}

Leeches for this thesis were purchased from LEECHES U.S.A. LTD. and placed directly into a refrigerator for about twenty four hours, or until leeches were sedated by the cool temperature. Leeches were then transferred to a container filled with a saltwater solution (2grams LE2004 HIRUDO® salt in one gallon distilled water). The container has two sections, one bucket with holes fitting inside another holding the saltwater. The container is filled about half way with the saltwater solution and the leeches are transferred from their arrival packaging to the container using large tongs. Both sections of the container have a top that must be taped down to prevent the leeches from leaving the container. The container is placed in the refrigerator to keep leeches sedated until they are used for experiments. Saltwater is replaced every one to two weeks or earlier if saltwater looks dirty. To replace saltwater, it is best to have a second container to transfer leeches into and then fill up with fresh saltwater. The dirty water is dumped down a drain and both sections of the container are rinsed with distilled water and left to dry until the next saltwater replacement. 


\subsection{Ganglia Extraction}

\subsubsection{Ganglia Extraction Tools}

Fifteen experiments were performed for this thesis. The following lists the tools used for a mid-body ganglion extraction from the leech in preparation for electrophysiological recordings:

Dissection Table

Glucose Ringer's Solution ( $\mathrm{pH} 7.4)$

Large Tongs

Leeches

Leech Mobile Home

Light Source

Micro Pins ( 5mm)

Microscope

Paper Towels
Push Pins

Refrigerator

Regular Ringer's Solution (pH 7.4)

Surgical Scalpel

Surgical Scissors

Surgical Tweezers (w/ curved tip)

Surgical Tweezers (w/ fine point)

Silicon-Filled Petri Dish (large)

Silicon-Filled Petri Dishes (small) x2

\subsubsection{Ganglia Extraction Procedure}

1. Leech Preparation 
a. Using large tongs, carefully grab one leech and place on large siliconfilled petri dish. Use tongs to hold leech down and use a pushpin to pin down one side of leech towards the edge of petri dish. Use a second pushpin to pin the other side of the leech and stretch to the opposite side of the petri dish. Cover the leech in Ringer's solution.

b. Use tweezers to pinch a small section of skin at one end of the leech, approximately $10 \mathrm{~mm}$ from the end, and cut incision using scissors. Now place one blade of the scissors in the incision and cut along the center of the leech, pulling up on the skin as to not cut too deep, for about $20 \mathrm{~mm}$. Pass scissors along incision a couple times to make sure top layer of skin is fully cut.

c. Use four more pushpins to stretch out both sides of the incision outward from the centerline of the leech, making of taut rectangle with one pushpin on each corner as close to the edge of the leech's skin as possible. Several ganglia should now be exposed. Use paper towels to absorb excess blood and then, again, cover with Ringer's solution. (Extra pushpins can be used to make a more taut rectangle). 


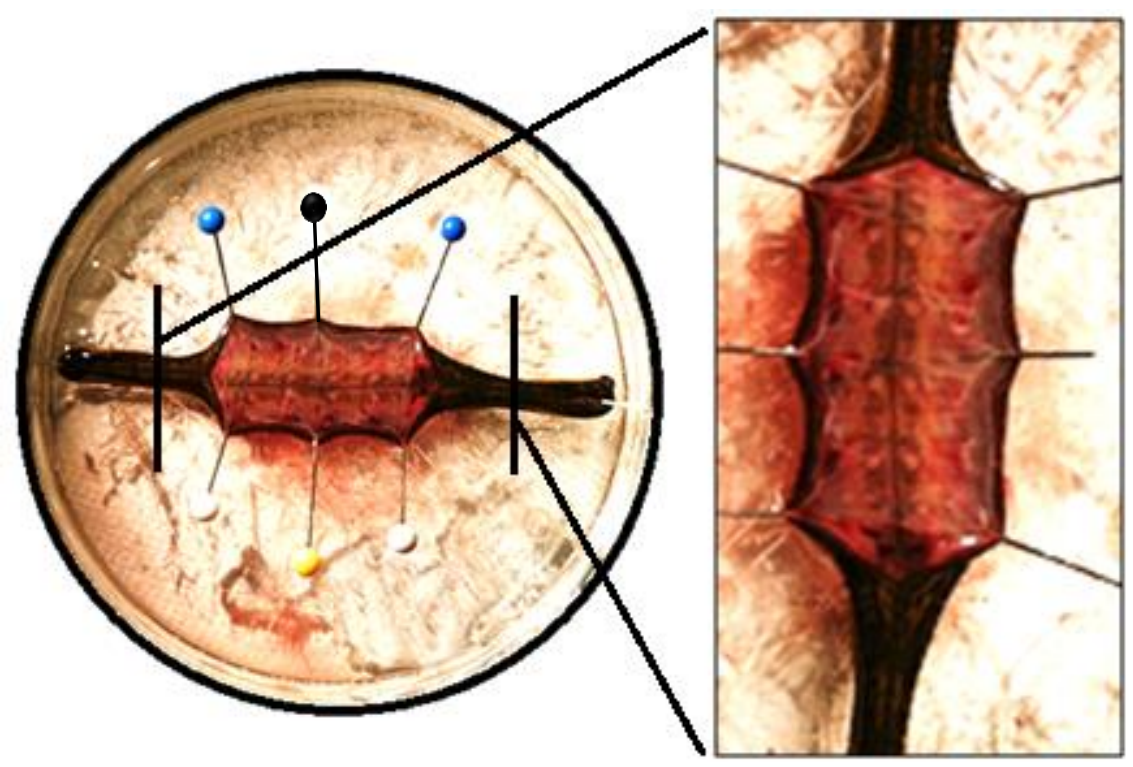

Figure 8.3 Example of leech pin-out and zoom-in of CNS

\section{Ganglia Preparation}

a. At this point, several ganglia are visible with the naked eye. Now use a microscope and focus on two ganglia of interest; in this experiment, it can be any of the ganglia except the four anterior and seven posterior.

b. Focus on one of the ganglia and begin by pulling and cutting away any remaining white tissue that protects the ventral nerve and organs. Switch to other ganglia and repeat.

c. Switching back and forth between ganglia, use the fine tip surgical tweezers and carefully pull away the dark fibers covering the ganglia and roots. Completely expose the ganglia and leave a small amount of dark fibers at the end of the thin roots to facilitate later pinning of the ganglia.

\section{Ganglia Extraction}


a. The ganglia, roots, and ventral nerve are now exposed. Focus on one ganglion and using sharp surgical scissors begin cutting the roots where they meet the muscle wall, keeping some of the protective fibers attached to the roots. This step is carried out on both sides of the ganglia until roots on either side are free from the muscle wall. Focus on other ganglia and repeat.

b. Now, cut the ventral nerve of both sides of each ganglion leaving enough length to later pin down the ends.

c. The ganglia are now free-floating. Carefully remove any instrument so as to not accidently pull out the ganglia. Prepare two small silicon-filled petri dishes, one with a bubble of regular Ringer's solution, the other with a bubble of glucose Ringer's solution. See note.

Note: The two dishes will be placed on the dark field microscope table that need to be in reach of the microscope view. To center the dishes on the microscope table, ganglia need to be as close to the side of their dish as possible. It is necessary to keep in mind which solution will go with which head stage. For example, if the regular Ringer's solution will go under head stage one, position the ganglion on the right side of the dish. Consequently, the glucose Ringer's solution will go under head stage two and the ganglion should be as close to the left side of the dish as possible. See Figure 8.4. 

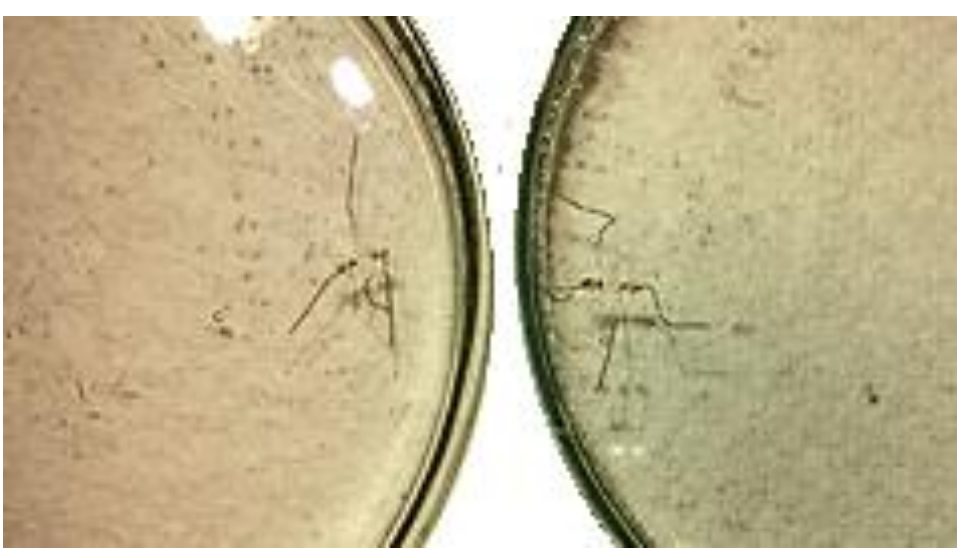

Figure 8.4 Example of ganglion positioning and micro-pin orientations

d. Using the curved-tip tweezers, carefully transfer the free-floating ganglion from the leech to its respective Ringer's solution bubble in the small petri dish. Make sure the ganglia stays in the bubble and does not float to an edge and dry out.

\section{Pinning-Out the Ganglia}

a. Starting with either ganglion, first focus the microscope on the ganglion. Using either or both tweezers, carefully push the ganglion to the bottom of the bubble. Try to straighten out and separate the roots so that the ganglion is flat against the silicon. Orient the ganglion so that the ventral side is facing up.

b. Have micro pins at hand and make sure the micro pin tips are sharp. Also, make sure one end of each micro pin is bent so that the ends run parallel with the silicone and do not stick straight up. 
c. Using one or both tweezers, pin either ventral nerve down to the silicone. Pin the other ventral nerve stretched across from the first pin so that the nerves are slightly taught.

d. Pin the remaining roots also slightly taught. It is best to pin the roots in the center of whatever fibrous tissue was purposely left on them.

e. Orient all bent sides of the micro pins to face away from the center of the ganglion and pin down securely. See note.

Note: Again, keep in mind which head stage the ganglion will be under and from which direction the pipette will be coming from. Continuing the example from the first note, regular Ringer's dish will have a pipette coming from left side, so orient the bent sides of pins away from the expected entryway of the pipette. See Figure 8.5. 


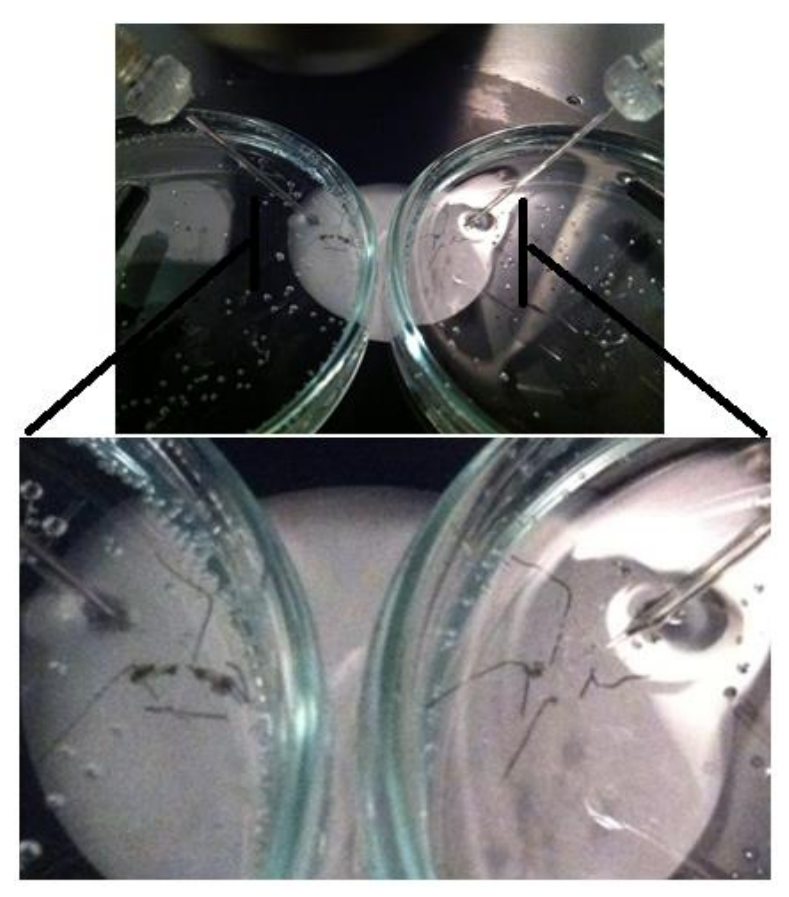

Figure 8.5 Final set-up having considered head stage and pipette entrance direction

f. Now, fill the petri dish with appropriate Ringer's solution so that the entire silicone bottom is covered and the ganglion is fully submerged.

g. Repeat steps a-f in section IV with the other ganglion.

h. Refer to Appendix B for leech carcass disposal protocol. 


\section{CHAPTER 9: ELECTROPHYSIOLOGICAL OVERVIEW AND EXPERIMENTAL PROTOCOLS}

Electrophysiology is the branch of physiology that studies the electrical activity of excitable cells and tissues. Various techniques can measure the movements of ions across surface membranes to provide information on ionic currents and membrane potential. Two common techniques used in electrophysiology include the voltage clamp and current clamp techniques. This section will introduce these two common techniques as well as describe, in detail, the electrophysiological procedures used for this thesis.

\subsection{Electrophysiological Recording Techniques}

Most bioelectric events, such as the action potential, will cause independent responses in two variables: the transmembrane current flow and the membrane potential. To study these responses individually, two techniques were developed in which one response is held constant while the other can be investigated. As indicated by their names, the voltage clamp technique holds the voltage constant, and the current clamp technique holds the current constant.

\subsubsection{Voltage Clamp}

The voltage clamp technique "clamps," or holds, the membrane potential at a constant value so that membrane currents can be measured independently. For this technique, two intracellular electrodes are necessary, one to measure the membrane potential (Ec), the other to pass current into the axon (Em). The voltage clamp amplifier

measures the difference between the intracellular membrane potential and the command voltage and then feeds current into the cell that is proportional to this difference. If the 
difference is zero $(\mathrm{Ec}=\mathrm{Em})$, the amplifier will not source or sink any current; if the difference is positive or negative, the amplifier will pass current proportional to that difference to either depolarize or hyperpolarize the cell until the membrane potential equals the command voltage (Ec). Lastly, a current meter connected to the output line of the amplifier is used to observe the current behavior in response to membrane potential. [27] A circuit diagram and conceptual representation of the voltage clamp technique is shown below in figures Figure 9.1 and Figure 9.2.

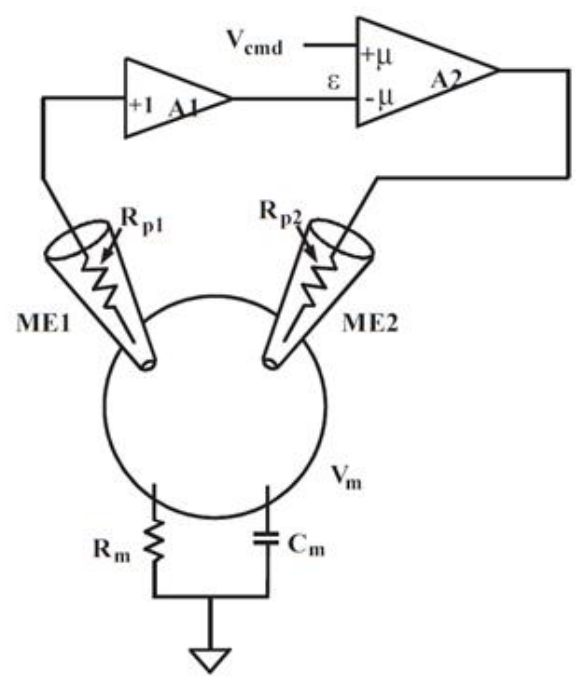

Figure 9.1 Circuit diagram of voltage clamp technique [37] 


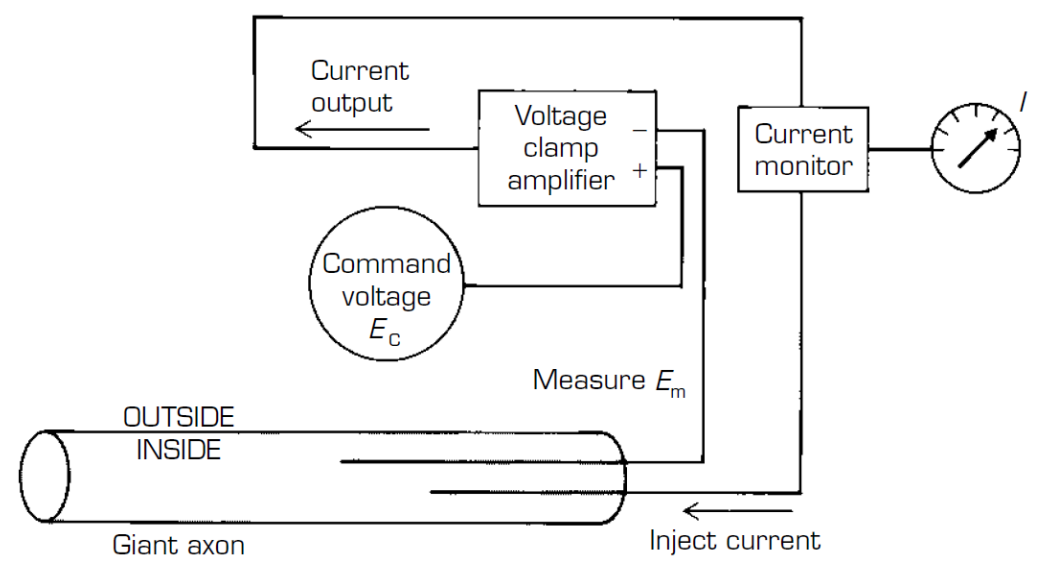

Figure 9.2 Conceptual representation of voltage clamp technique [27]

\subsubsection{Current Clamp}

The current clamp technique "clamps", or holds, the membrane current at a constant value so that changes in membrane potential can be measured independently. The essence of this technique is the connection of a micropipette to a unity gain buffer amplifier whose input resistance is orders of magnitude larger than that of the micropipette resistance. [37] A unity gain buffer has a gain of one, meaning output voltage is equal to input voltage, thus, the output voltage follows the voltage at the end of the electrode. Since an ideal buffer amplifier draws in no current, we can assume the current through the pipette is "clamped" at zero. [37] An amplifier in the configuration shown below that is connected to the input node will source or sink all the current down the micropipette and be used to stimulate the cell. Membrane potential can then be measured as it depolarizes or hyperpolarizes in response to particular current values. A circuit diagram for the current clamp technique is shown below in Figure 9.3. 


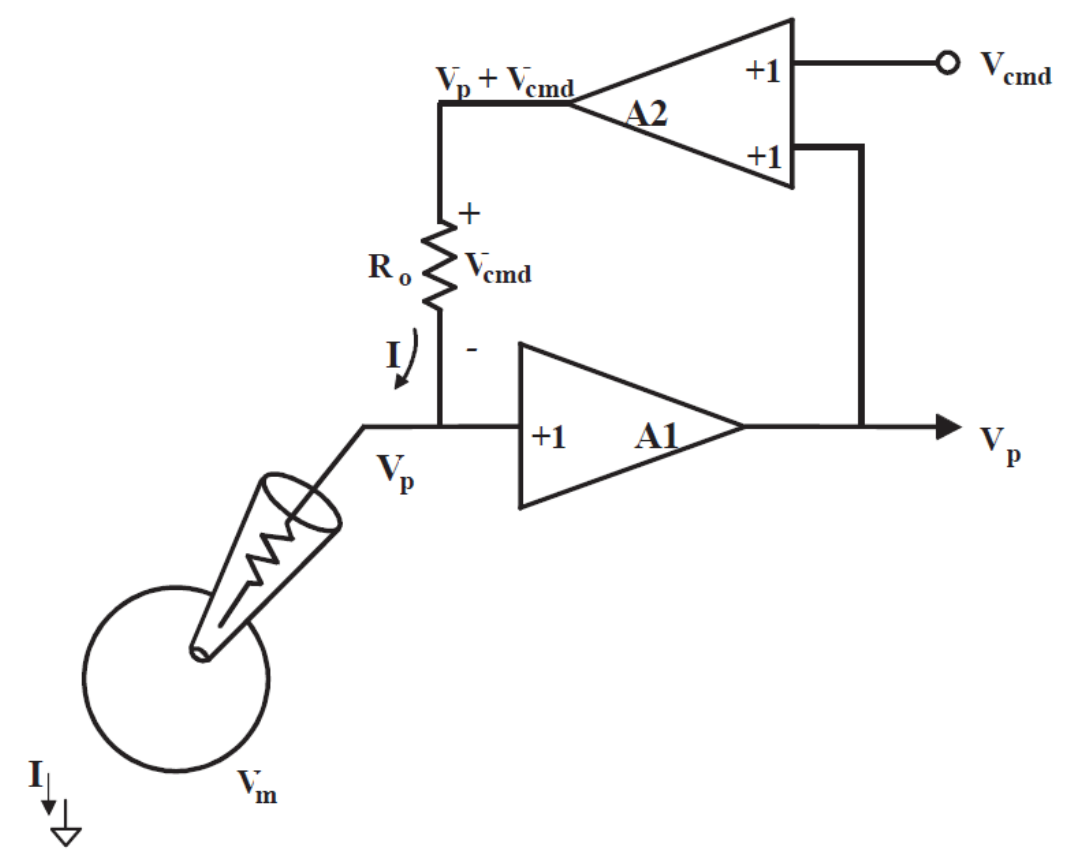

Figure 9.3 Circuit diagram of current clamp technique [37]

\subsection{Experimental Procedure}

This procedure was designed to investigate the difference in longevity of action potential recruitment in a Retzuis cell in glucose Ringer's solution versus a Retzius cell in regular Ringer's solution. The timing started when the ganglia were removed from the leech and placed in their respective solution. Every twenty to thirty minutes, sufficient stimulus was injected simultaneously to both Retzius cells to depolarize their membrane potentials past threshold to recruit and record action potentials. This process of stimulating and holding the membrane current at a particular amplitude for a designated amount of time is an example of the current clamp technique described above. The experiment was continued until action potentials could no longer be recruited from the chosen Retzius cell. Below is a table showing a typical experiment timetable: 
Table 9-1 Typical timeframe from leech dissection to apparent cell death

Dissection

In Ringers

First Stimulation

Second Stimulation

Subsequent Stimulations

Subsequent Stimulations (post 3hrs)
00:00

00:15-00:30

00:30-00:40

Every 20 minutes until 3:00

Every 10-15 minutes until not more action

potentials can be recruited

About two to ten stimulations were introduced, as necessary, at every stimulation time to recruit and record action potentials in both Retzius cells. The exact number of stimulations at exact intervals across experiments was not recorded since it was not necessary as this experiment was intended to measure the difference in longevity of action potential recruitment and not their total survival time. However, the total number of stimulations per experiment was recorded to compare to the total survival time and check for any correlation. All possible precautions were taken so that both cells would experience, and be affected equally, by the same dissection and stimulation protocols. 


\subsubsection{Equipment}

The following lists the tools used to perform the electrophysiological recordings in the leech:

3M Potassium Chloride Solution

Axoclamp 900A amplifier

Axoclamp 900A software

Clampex 10.2 software

Clampfit 10.2 software

Computer

Dark Field Microscope

Digidata 1440a DAQ unit

Extracted leech ganglia

Faraday cage

Head stage $\mathrm{x} 2$
Lighting

Microfil

Micropipettes

Micropipette Puller

Oscilloscope

Recording electrodes

Ringer's Solution (Regular and Glucose)

Silver Silver-Chloridized wires

Screwdrivers to adjust head stages

Small petri dish

Syringe

\subsubsection{Equipment Setup}

The experimental set-up consists of several hardware and software components. Recording of electrical signals occurs at the "recording site" which is composed of two extracted ganglia in separate, small petri dishes. The two dishes are placed side by side 
under a dark field microscope within a faraday cage. Two recording electrodes are placed in the recording site, one for each ganglion, using adjustable head stages. Two reference electrodes, one for each petri dish, are placed in by hand. The Axoclamp 900A amplifier is set up so that the recording and reference electrodes are configured as a current clamp. The amplifier magnifies the signal's amplitude where it is then displayed on an oscilloscope and read by the computer and Digidata 1440a DAC unit. The computer, also set up to receive information from the Digidata 1440a DAC unit, can now be used to analyze the signal. The Axoclamp software is used to calibrate the equipment and monitor electrode impedance. The Clampex and Clampfit softwares are used to record, stimulate, observe, and analyze membrane potential recordings. A conceptual equipment setup diagram is shown in Figure 9.4.

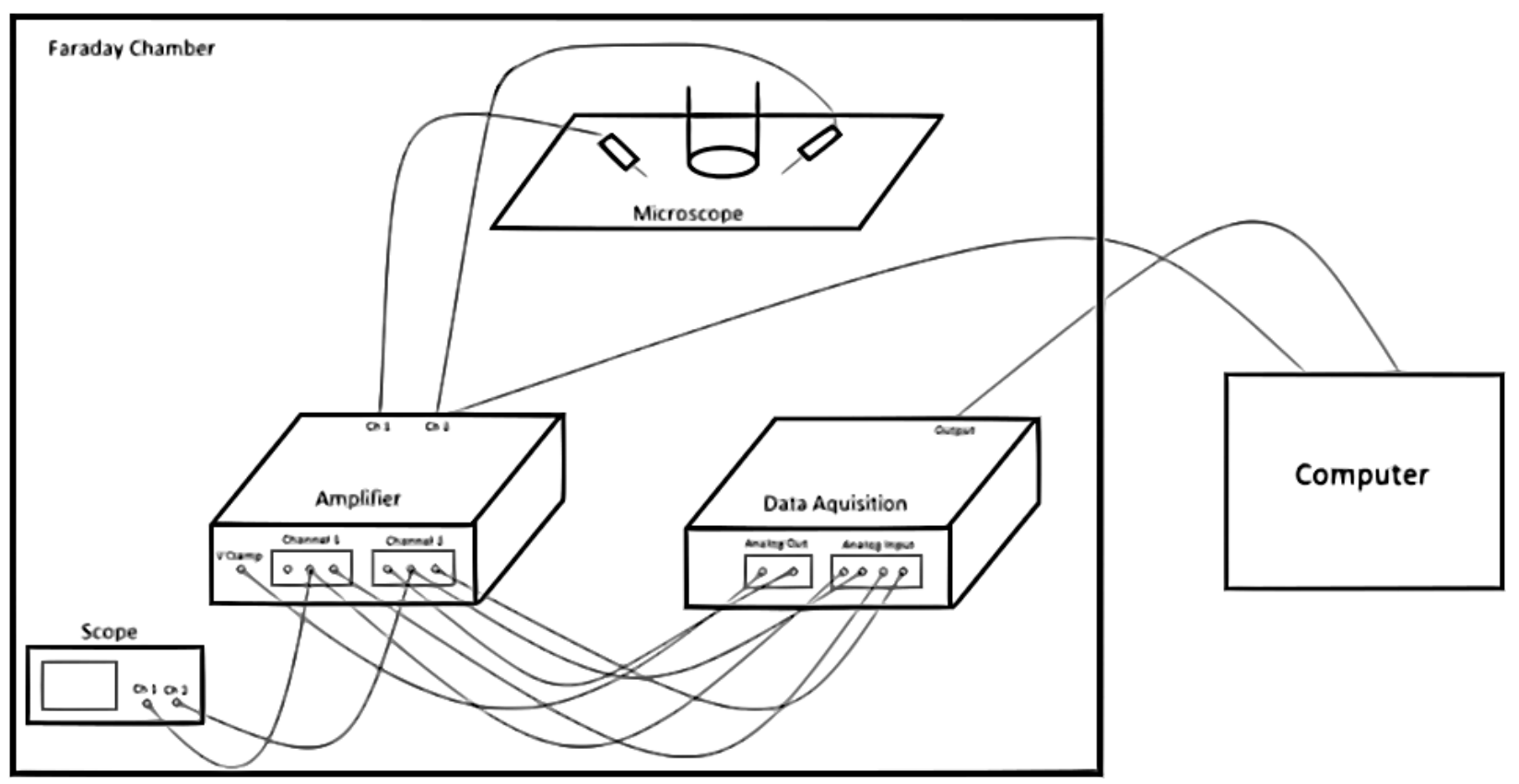

Figure 9.4 Conceptual representation of equipment set-up 


\subsubsection{Electrodes and Noise Reduction}

In this type of experiment, we were working with very fragile organisms and very small electrical signal amplitudes ( $\mathrm{mV}$ and $\mathrm{nA})$. As such, it is crucial to use electrodes that can penetrate the cell membrane without causing considerable damage as well as equipment that can remain sensitive enough to detect such small signals. To manage these criteria, glass capillary microelectrodes, or micropipettes, were used within a Faraday cage. Micropipettes are hollow glass cylinders that are heated and pulled to form a sharp tip. The micropipettes are filled with $3 \mathrm{M}$ potassium chloride solution with MicroFil TM syringes and are then slid over silver silver-chloridized wires attached to the head stages. Each head stage has a paired, standard reference electrode that is placed in the same Ringer's solution bath as the micropipette tip to complete the circuit. All recordings are performed in a Faraday chamber to minimize the amount of unwanted electrical interference coming from sources such as the computer, lighting, and electrical outlets.

\subsubsection{Micropipette Preparation}

The following describes the steps to arrange two head stages with micropipettes in preparation for equipment calibration and cell recording implementation:

1. Make sure Axoclamp amplifier is turned off before handling electrodes.

2. Pull two or more pipettes with the micropipette puller. Refer to APPENDIX C for detailed instructions.

3. Place a silver silver-chloridized wire on each head stage. 
4. Fill micropipette with $3 \mathrm{M} \mathrm{KCL}$ solution using a microfil attached to a syringe. Make sure to remove any air from syringe first and that microfilm reaches maximum depth of pipette when filling with solution. Slowly pull microfil out while injecting solution.

5. Slide the filled micropipettes over the silver silver-chloridized wires and tighten to head stage.

6. Place a petri dish filled with original Ringer's solution between both head stages and, using the adjustments, carefully insert the tip of each micropipette into the Ringer's solution. You will notice a little dimple in the solution when the pipette tip has entered the solution.

7. Carefully place both ground electrodes in the Ringer's bath to complete the circuits.

\subsubsection{Calibration Protocol}

The following lists the steps for calibrating the electrodes and preparing equipment for cell recording:

1. Turn on computer, Digidata 1440A DAQ unit, both oscilloscopes, and the Axoclamp 900A amplifier.

2. Open the Axoclamp 900A software. 


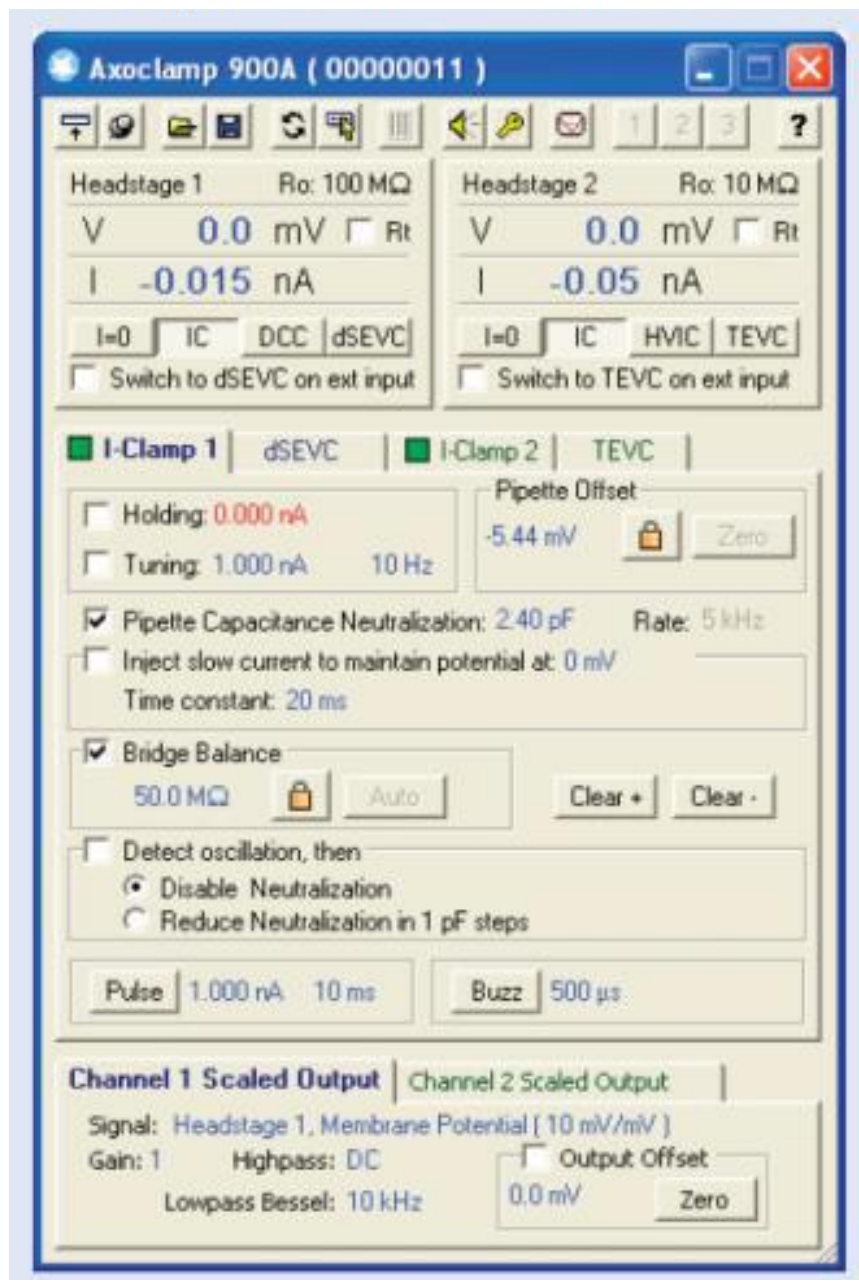

Figure 9.5 Axoclamp commander software interface

3. On the Axoclamp Commander Software Interface, make sure both head stages have IC selected.

4. Using the I-Clamp 1 and I-Clamp 2 tabs, make sure pipette capacitance and bridge balance are unclicked on both head stages (I-Clamp 1 is for head stage 1 and I-Clamp 2 is for head stage 2).

5. Check the pipette resistance by checking the Rt box next to the voltage display. The resistance must be between $20 \mathrm{M} \Omega$ and $80 \mathrm{M} \Omega$. If the resistance is not within that range, repeat the micropipette preparation procedure until the resistance is correct. 
6. In the pipette offset box, click the lock and then zero. This zeros the position of the potential.

7. Starting with head stage 1 , on the I-Clamp 1 tab, check the tuning box. Change the source on the oscilloscope to $\mathrm{CH} 1$ and, using the Trigger knob, move the arrow to fit within the pulse train to lock the signal.

8. Check Pipette Capacitance Neutralization and adjust its value until the rising edge of the pulse has a slight overshoot. This step removes any stray capacitance that can have a negative impact on the bandwidth of the recording. An example of stray capacitance can be seen in Figure 9.6 a) and b).

9. Check the Bridge Balance box and adjust its value until the pulse train displays a straight line. The value will be close to that of the resistance value, as this step is calibrating out the micropipette resistance (Rp). Passing current through the electrode produces a voltage drop across the electrodes resistance (I Rp). When subtracting that voltage drop from the total voltage $(\mathrm{Vp})$, only membrane potential is left $(\mathrm{Vm})$. See Figure 9.6. This concept can be represented by the equation shown below.

$$
V p-I R p=V m \ldots \ldots \ldots \ldots \ldots \ldots \text { Equation } 4
$$

10. Once again, zero the pipette offset. Now, only Pipette Capacitance Neutrality and Bridge Balance should be checked.

11. Repeat steps 7-10, now for head stage 2.

It is necessary to calibrate the electrodes with every new experiment. As seen in Figure 9.6 b), the capacitance, resistance, and voltage associated with the pipette creates a low pass filter. Calibrating removes the capacitance, opening the 
circuit and removing the filtering, thus allowing for a wider range of frequencies to be observed.

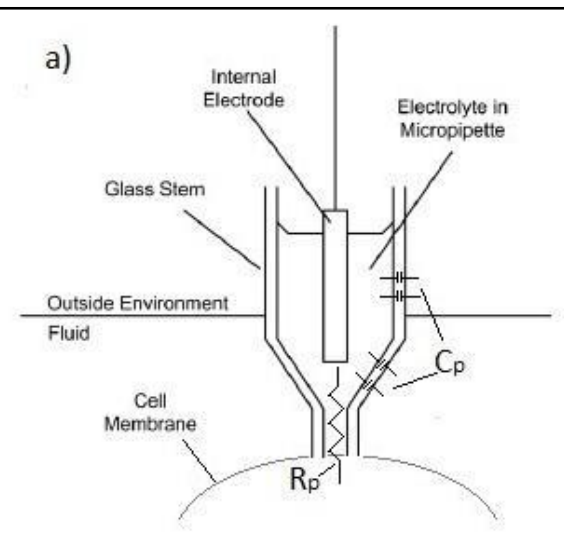

b)

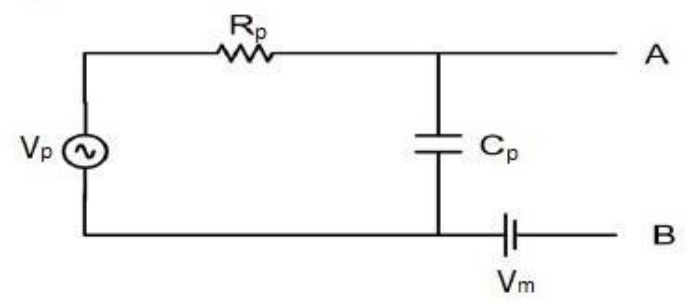

Low pass filter c)

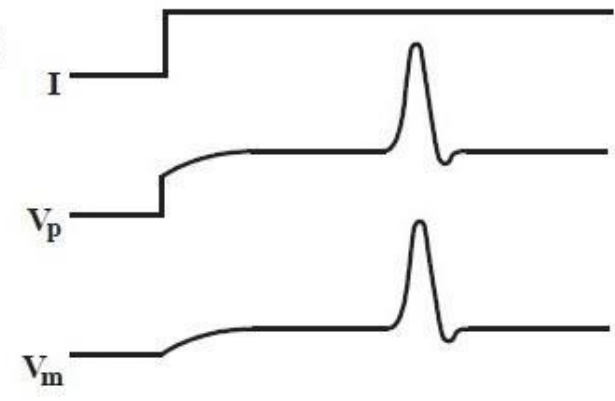

$\left(V_{p}=V_{m}+I R_{p}\right)$

Figure 9.6 Capacitance and resistance calibration

\subsubsection{Cell Recording Implementation}

After the completion of the dissection and calibration protocols, cell recording can begin. The following lists the steps involved in visualizing a Retzius cell, inserting the pipette into the Retzius cell, stimulating and recording action potentials for two ganglia in different petri dishes: 


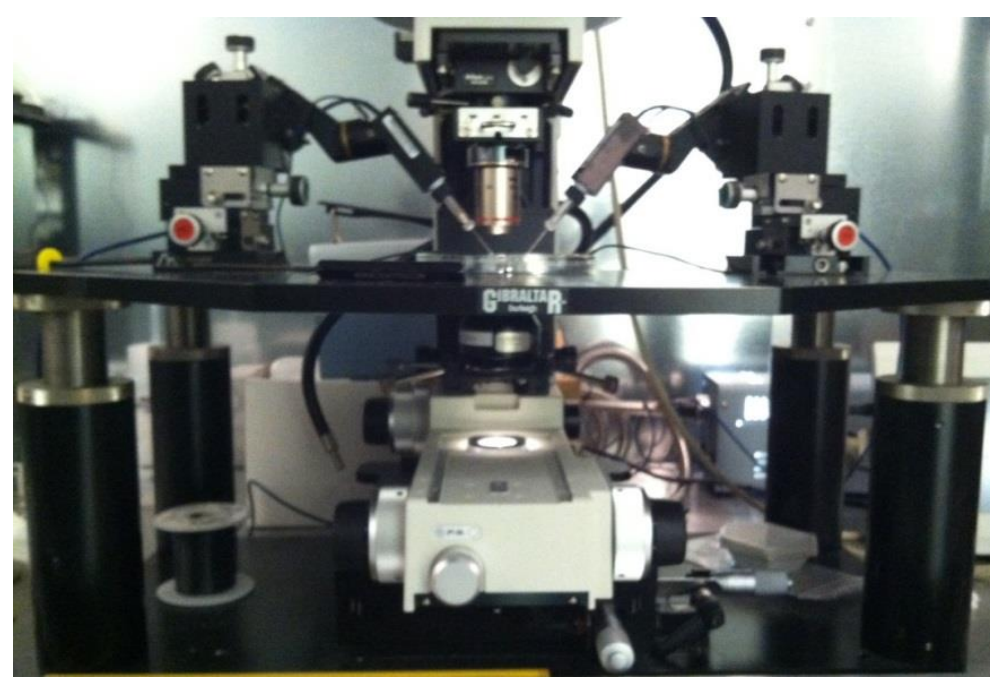

Figure 9.7 Electrophysiological recording

1. Turn off the Axoclamp amplifier and remove pipettes from petri dish containing the Ringer's solution used for calibration of the pipettes.

2. Place both petri dishes containing the pinned down ganglia under the dark field microscope. It would be wise to face pipettes towards the back and out of the way while placing the petri dishes under the microscope to avoid accidentally hitting the pipettes. Orient the dishes so that the pinned down ganglia are right next to one another, both within the center of view of the microscope.

3. Using the $4 \mathrm{X}$ magnification, bring one of the ganglia into focus. Adjust the center of view, microscope lighting and focus using the respective knobs below the head stage table to center and clearly visualize the ganglia and the Retzius cells.

4. Now inspect the ganglia for any appreciable damage or abnormalities. Repeat the dissection protocol if any damage or abnormalities are found. Check the orientation of the micro pins and make any necessary adjustments if they are not properly oriented.

5. Repeat steps 3 and 4 for the other ganglia. 
6. Once both petri dishes and ganglia are correctly positioned under the microscope, use the adjustable head stage to bring the tip of the pipettes into the Ringer's solution of the petri dish closest to it. Insert the reference electrodes into their corresponding dish.

7. Turn on the Axoclamp amplifier and re-check the electrode impedances on the Axoclamp software interface. Impedance values must be between $20 \mathrm{M} \Omega$ and 80 $\mathrm{M} \Omega$. If either is not in that range, repeat the micropipette preparation and calibration protocol for the necessary replacement micropipette(s).

8. Starting with either ganglion, use the fine adjustments on the head stage to bring the pipette as close to the ganglia as possible. Then use the $4 \mathrm{X}$ eye to visualize the tip of the pipette. The tip of the pipette will be just under the surface of the Ringer's solution and focal length adjustment will be necessary to bring it into view.

9. Continue to use the head stage fine adjustments to bring the tip of the pipette directly over the center of the ganglion. Lower the pipette while simultaneously adjusting the focus to always keep the tip of the pipette in focus until the pipette is close, but not touching the ganglion.

10. Now, identify the Retzius cell using the ganglion map shown in Figure 8.2 A. Keep in mind, orientation of the pinned ganglion may not be consistent with the orientation seen in the map.

11. Once the Retzius cell is identified, use the head stage fine adjustments to move the pipette to the side of the Retzius cell. Puncturing of the cell membrane will occur on the side of the cell that is closest to the head stage, meaning the pipette should not be reaching over the cell, rather it should be just barely approaching it.

12. Once the pipette tip is on the correct side of the cell, continue using the fine adjustments to carefully insert the tip into the cell. If the pipette looks like it is 
puncturing the cell but no voltage drop is observed on the oscilloscope, the head stage adjustment can be softly tapped to help the tip into the cell.

13. If the micropipette tip is in the cell, a drop in voltage will be observed on the oscilloscope on the order of -30 to $-40 \mathrm{mV}$, assuming the voltage was zeroed prior to entering the cell. Spontaneous depolarizations will also occur without stimulation.

14. Repeat steps $8-13$ for the other ganglia.

15. Once the pipettes are in both Retzius cells, use the Clampex software to stimulate and record action potentials.

\subsection{Stimulation and Action Potential Recruitment Parameters}

As mentioned before, both cells (one in each solution) were stimulated simultaneously with the same parameters. Stimulation values ranged from .1 to .3 nanoAmps (most at $.3 \mathrm{nA}$ ) for a duration of 50 milliseconds. The range of stimulation amplitude occurred when low amplitude was insufficient for action potential stimulation. Number of stimulation repeats depended on action potential recruitment for both cells; some stimulation times (usually earlier in the experiment) required only a few stimulations to record action potentials in both cells, while others (usually later in the experiment) required several stimulations to record action potentials in both cells. Number of stimulations per experiment was recorded and analyzed to check for any correlations to longevity of cell survival. 


\section{CHAPTER 10: RESULTS AND CONCLUSIONS}

Several analyses were done on the data collected to check for any impact on longevity of Retzius cell survival in regular Ringer's solution compared to glucose Ringer's solution. Experiments were performed with the intention that all steps of the experiment affected both Retzius cells (one in each solution) identically and simultaneously. Minitab ${ }^{\circledR}$ Statistical Software and Matlab ${ }^{\circledR}$ Mathworks Inc were used to perform basic statistical analysis to discover if glucose Ringer's solution would keep a Retzius cell alive longer than regular Ringer's solution. This section will show results for analyses done on factors that may have impacted cell longevity as well as document any conclusions that can be made from said analyses. Please refer to Appendix D for all Minitab ${ }^{\circledR}$ Statistical Software and Matlab ${ }^{\circledR}$ Mathworks Inc raw analysis outputs and codes.

\subsection{Action Potential Recordings}

Clampex software was used to stimulate and record action potentials. Most stimulations were done with an amplitude of $.3 \mathrm{nA}$ for a duration of $50 \mathrm{~ms}$. Each stimulation automatically recorded $500 \mathrm{~ms}$ of data. Figure 10.1 shows examples of what recorded Retzius cell action potentials look like at the beginning of an experiment (30mins to an hour in) versus what they look like towards the end (3-5 hours in). When no evidence of an action potential was recorded after repeated stimulations, the cell would be assumed dead and total cell survival time recorded and used for data analysis. 


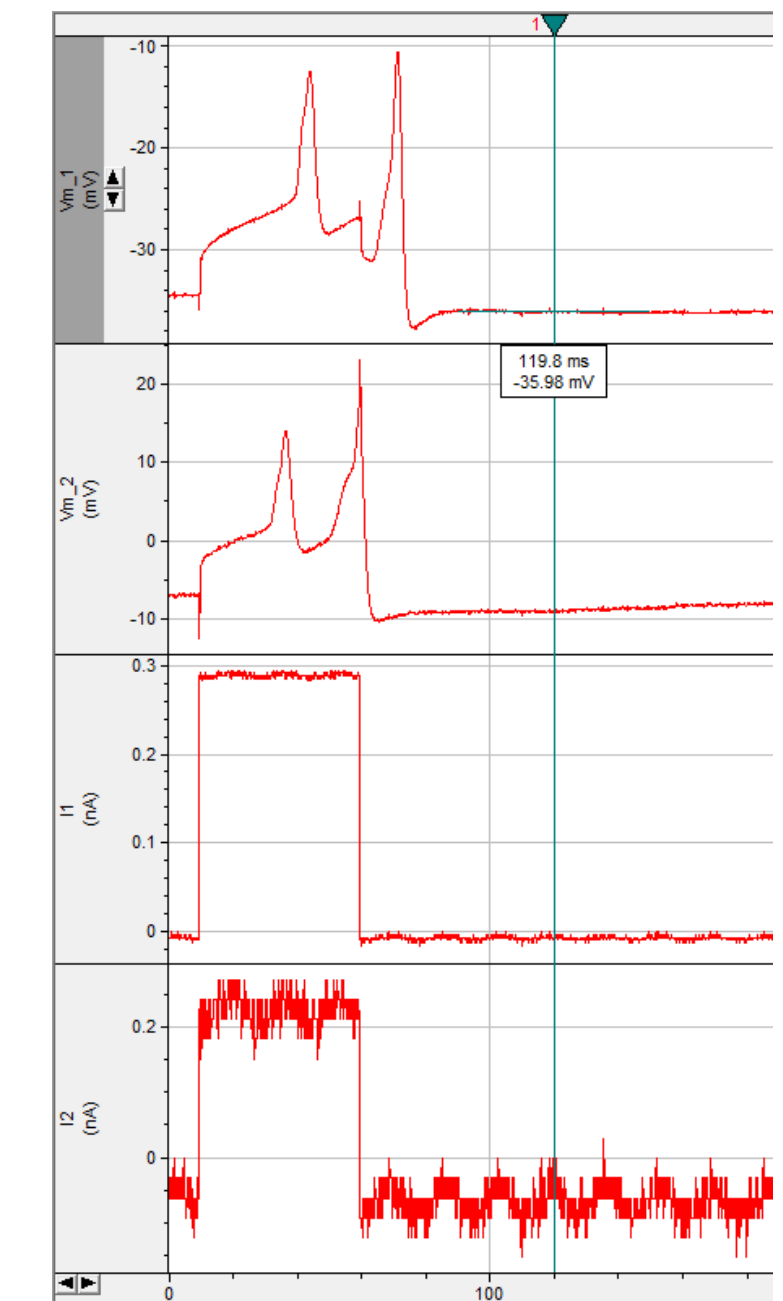

A. 1

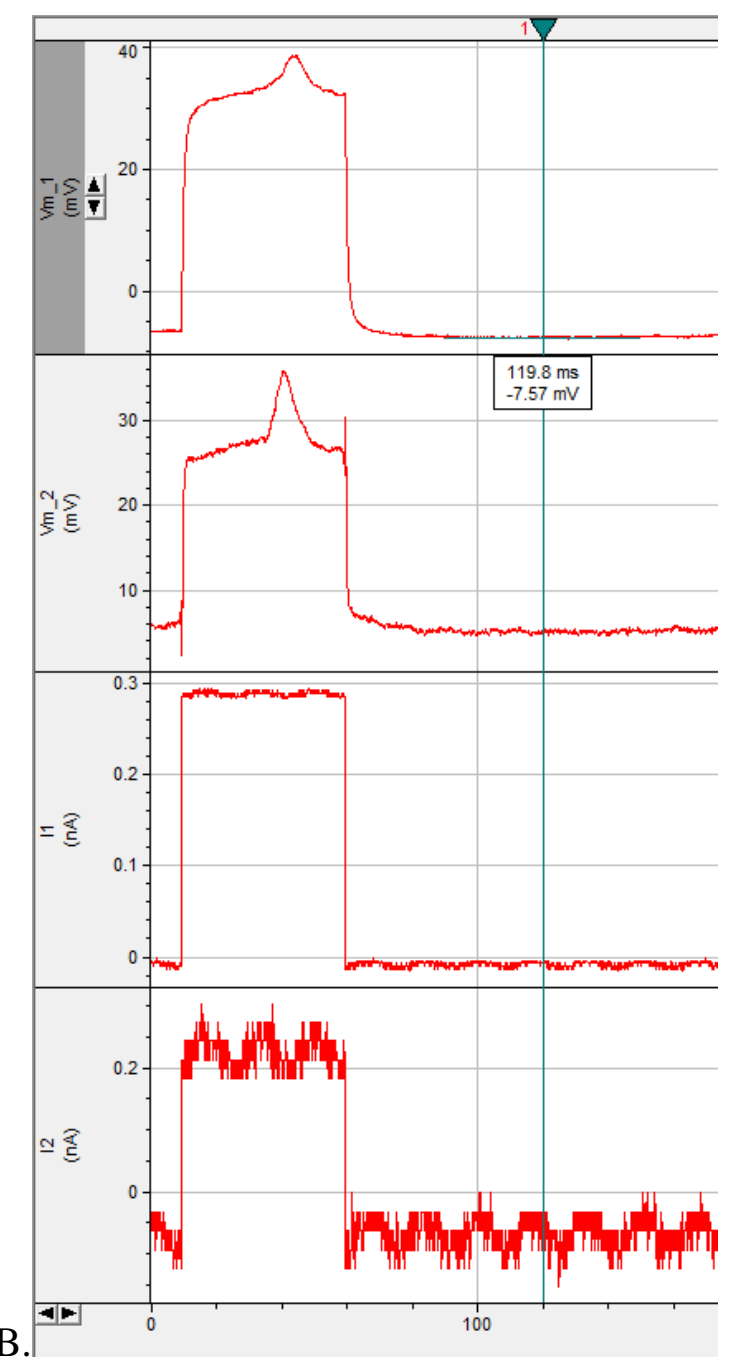

B.

Figure 10.1 Clampex software action potential recordings A. Early in experiment B. Later in Experiment

\subsection{Survival Time of Retzius Cells in Ringer's Solutions}

The goal of this thesis was to determine whether or not a glucose-enriched Ringer's solution would extend the longevity of a leech Retzius cell when compared to a regular Ringer's solution which does not contain glucose. The hypothesis was that a glucose-enriched solution would in fact allow for a longer experimental time frame. Matlab $^{\circledR}$ Mathworks Inc was used to plot the mean survival times of the Retzius cell in 
both solutions. See Figure 10.2 below. Basic statistics performed using Minitab ${ }^{\circledR}$ Statistical Software provided the values used to make this plot. The mean survival time of the Retzius cell in regular Ringer's solution was 210.7 minutes with a standard deviation of 68. The mean survival time of the Retzius cell in glucose-enriched Ringer's solution was 256.0 minutes with a standard deviation of 47 .

A paired student t-test was performed using Minitab ${ }^{\circledR}$ Statistical Software to determine whether or not the Retzius cell survival time was significantly greater than the survival time in regular Ringer's solution. For this test, the difference of means was set to thirty minutes. This value was chosen as the minimal amount of time that would make the addition of glucose to Ringer's solution worthwhile by allowing significant increased longevity to make alterations to an experimental paradigm. The paired t-test was run with a $95 \%$ confidence interval and results gave a T-value of 0.84 and a p-value of 0.207 . These values indicate that glucose Ringer's solution did not significantly extend the longevity of the Retzius cell by thirty minutes compared to regular Ringer's solution.

A second paired t-test was performed to check for any statistical difference between the survival times of the Retzius cell in glucose Ringer's solution versus regular Ringer's solution. The means were compared with a 95\% confidence interval and gave a T-value of 2.49 and a p-value of 0.026 . These values demonstrate that there is a statistical difference between the survival rates of the Retzius cell in glucose Ringer's solution versus regular Ringer's solution with a 95\% confidence that the Retzius cell in glucose Ringer's solution will survive between 6.3 and 84.3 minutes longer than the Retzius cell in regular Ringer's solution. 


\section{Comparison of Retzius Cell Survival Times in Ringer's Solution and Glucose enriched}

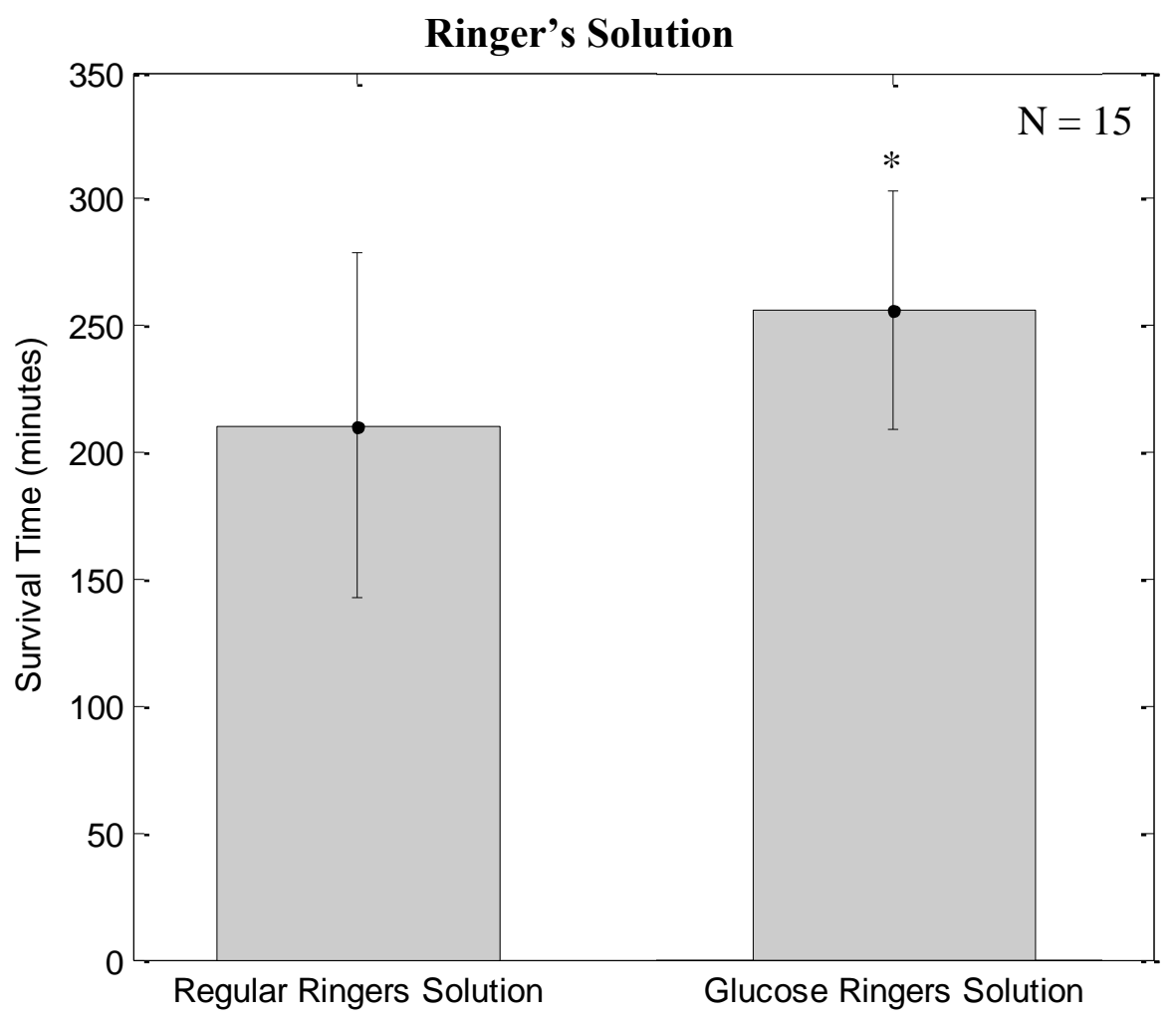

Figure 10.2 Bar graph showing the mean survival times of Retzius cell submerged in regular Ringer's solution versus glucose Ringer's solution. * indicates P-value $<.05$ with mean difference equal to 0.

\subsection{Stimulation Correlation}

In order to perform further analysis, it was necessary to clarify the effect stimulations may have had on the survival time of the cells. Each experiment had a different number of stimulations depending on two things: action potential recruitment (action potentials recorded in both cells) and cell survival time (the longer the cells survived, the more stimulations they would receive). If stimulations impacted cell longevity, it would not be 
possible to compare total survival time across experiments because the number of stimulation would introduce an additional variable. However, if number of stimulations shows no correlation to cell longevity, we could use total survival time of the cells for further analysis.

Minitab $^{\circledR}$ Statistical Software was used to create the scatterplot shown in Figure 10.3 to show possible correlations between cell longevity and number of stimulations. Each point represents the survival time of individual experiments and is plotted as a function of the number of stimulations for that particular experiment. Black markings represent experiments in regular Ringer's solution and red markings represent experiments in glucose Ringer's solution. Linear regression analysis completed on this data shows that cell longevity in neither regular Ringer's solution nor glucose Ringer's solution has any correlation to number of stimulations with an $\mathrm{R}$ squared value of $0.6 \%$. 


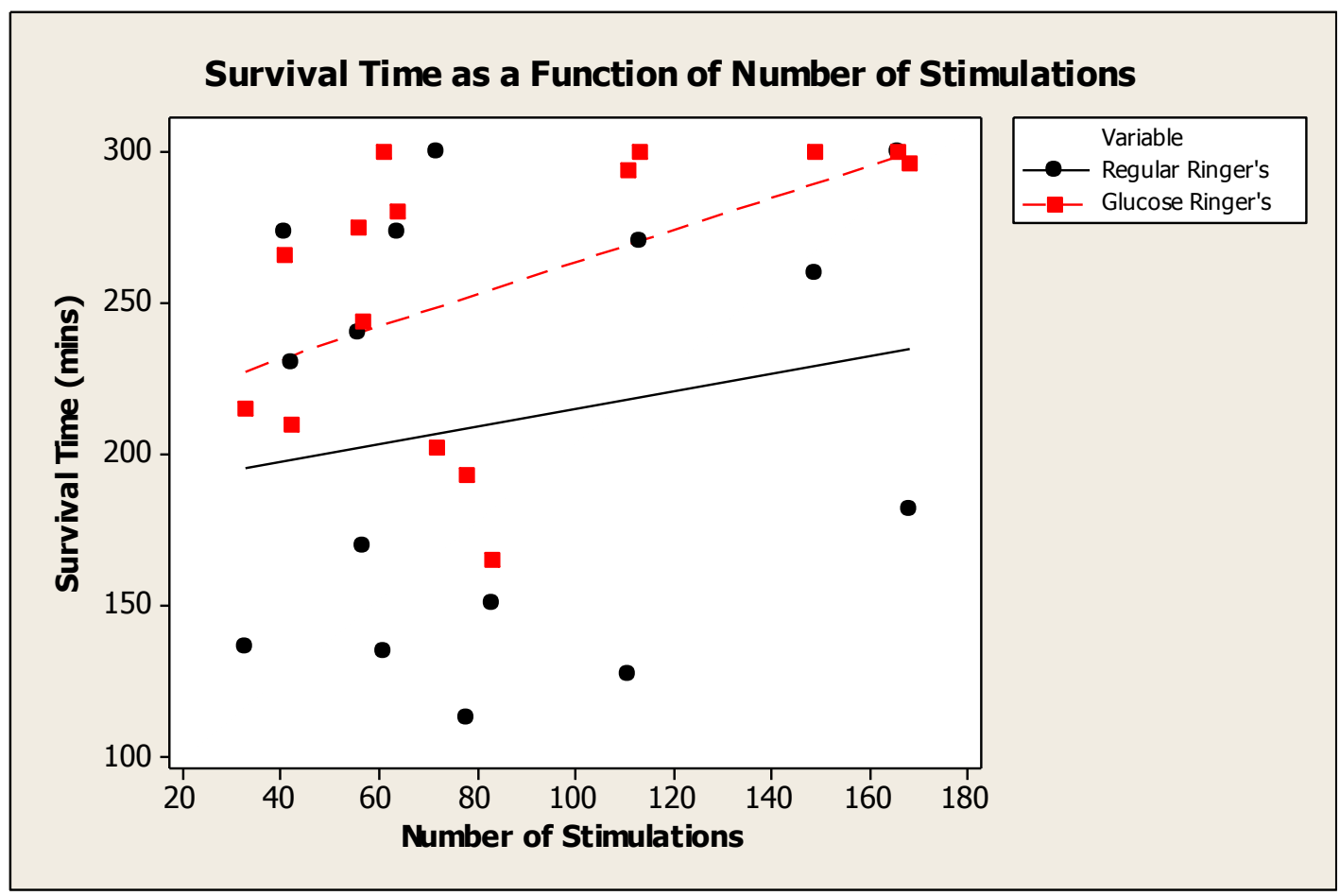

Figure 10.3 Scatter plot comparing regular Ringer's solution and glucose Ringer's solution to number of stimulations

\subsection{Head-Stage Impact}

The last variable that was tested to check for any effect on cell longevity is the head-stages used during the experiment. Fifteen experiments were performed; eight with regular Ringer's on head-stage one and seven with glucose Ringer's on head-stage one. Minitab $^{\circledR}$ Statistical Software was used to perform two two-sample Student's t tests to verify any correlation between cell longevity and either head-stage one or head-stage two. Analysis showed that neither head-stage impacted cell longevity with a p value of 0.33 when comparing head-stages to cell survival in regular Ringer's solution and a $\mathrm{p}$ value of 0.517 when comparing head-stages to cell survival in glucose Ringer's solution. 


\subsection{Conclusions}

Analysis of the data disproved the hypothesis that glucose Ringer's solution will keep the Retzius cell alive at least 30 minutes longer than regular Ringer's solution does. There is, however, a significant difference in the overall average longevity of the Retzius cell in glucose Ringer's solution versus regular Ringer's solution when the difference of means is set to zero. Additionally, the graph comparing stimulation and survival time shows the glucose data points at higher survival rates. Although the graph analysis demonstrates no significant correlation between stimulation number and survival, glucose does seem to be able to help the cells in some measurable way. Lastly, the head stages were the tested for impact on cell longevity and analysis has shown that neither head stage impacted cell longevity in either solution. 


\section{CHAPTER 11: DISCUSSION}

This thesis was attempting to extend the longevity of cells being studied in vitro for electrophysiological purposes. It was thought that due to the minimal glucose storage of nerve cells, glucose deficiency may be the cause of cell death. Glucose was added to regular Ringer's solution to supply the cell with adequate amounts of fuel to produce ATP, and perhaps, cause it to live longer than it would in regular Ringer's solution alone. Results concluded that the addition of glucose to Ringer's solution did not extend the life of cells significantly (at least 30 minutes) to justify adding glucose to regular Ringer's solution. It would be interesting to understand what, if not lack of fuel, is causing the cells to die after 3-5 hours into the experiment.

When considering what a nerve cell needs to survive, aside from its osmotic extracellular environment, glucose and oxygen are critical for cells to sustain their membrane potential. With this in mind, it can be considered that glucose is not able to get into the cell from the extra-ganglionic solution. In addition, perhaps oxygen supplied from Ringer's solution's contact with the air is not sufficient for the cell to produce adequate amounts of ATP. Ideas for future studies include investigation of whether or not the cells are getting access to the glucose provided in the Ringer's solution as well as aerating the solution in a manner similar to aeration of fish tanks. A "flowing system" is commonly used in electrophysiogical experiments and can be used to supply a fresh, glucose-enriched, aerated solution to the ganglia throughout the entire experiment.

Additionally, there are a few variables difficult to control that occur with experiments such as the ones in this thesis that could potentially impact cell longevity. 
The first is the dissection protocol. As much as one tries to perform dissections equally across experiments, there can be differences in time or effort required to remove ganglia. Remember, the protocol calls for using a surgical tweezers to remove all protective covering from the ganglia. This includes applying pressure and a general disturbing of the ganglia. It is necessary to be very careful during this procedure and also when inspecting for any appreciable damage that may have occurred during dissection that would require a repeat of the procedure.

Lastly, but perhaps most importantly, is the need to puncture the cell membrane for cell stimulation and action potential recordings. The experimental procedure followed in this thesis attempted one "puncturing" of the cell membrane for stimulating and recording purposes, but additional re-entering of the cell was very often necessary as the pipette would get "pushed" out of the cell and need to be reinserted. Based on observation only, it seemed that the experiments tended to last longer when very few pipette adjustments were necessary throughout the experiment, versus other experiments that required many re-insertions of the pipette. This variability is difficult to control, but I would hypothesize that the puncturing of the cell membrane is a contributing factor affecting cell longevity.

In summary, although the addition of glucose to Ringer's solution did not extend the life of the Retzius cell by at least thirty minutes when compared to regular Ringer's solution, some measurable difference was statistically shown. With this information, the addition of glucose to Ringer's solution may in fact be beneficial to cell survival. All possible precautions were taken to eliminate variables that would affect 
longevity and those possible to test were found to have no correlation and therefore no appreciable effect on cell survival time. 


\section{REFERENCES}

1. Hudson, R.P., Lessons from Legionnaires' Disease. Annals of Internal Medicine, 1979. 90(4): p. 704-707.

2. Control., C.f.D., G.A. Hébert, and G.L. Jones, "Legionnaires" : the disease, the bacterium, and the methodology / edited by Gilda L. Jones and G. Ann Hébert1979, Atlanta :: U.S. Dept. of Health, Education, and Welfare, Public Health Service, Center for Disease Control, Bureau of Laboratories.

3. Ellis, H., Sydney Ringer: physician, physiologist and pharmacologist. British Journal of Hospital Medicine (2005), 2010. 71(11): p. 645-645.

4. Hurst, J.W., W.B. Fye, and H.-G. Zimmer, Sydney Ringer, serendipity, and hard work. Clinical Cardiology, 2005. 28(1): p. 55-56.

5. Lee, J.A., Sydney Ringer (1834-1910) and Alexis Hartmann (1898-1964). Anaesthesia, 1981. 36(12): p. 1115-1121.

6. Miller, D.J., Sydney Ringer; physiological saline, calcium and the contraction of the heart. The Journal of Physiology, 2004. 555(3): p. 585-587.

7. Ringer, S., Concerning the influence exerted by each of the constituents of the blood on the contraction of the ventricle. The Journal of Physiology, 1882. 3(5-6): p. 380393.

8. Ringer, S., A further Contribution regarding the influence of the different Constituents of the Blood on the Contraction of the Heart. The Journal of Physiology, 1883. 4(1): p. 29-42.3.

9. Sternbach, G., Sydney Ringer: water supplied by the new river water company. The Journal of Emergency Medicine, 1988. 6(1): p. 71-74.

10. Locke, F.S., On a Supposed Action of Distilled Water as such on certain Animal Organisms. The Journal of Physiology, 1895. 18(4): p. 319-331.

11. Locke, F.S., Towards the Ideal Artificial Circulating Fluid for the Isolated Frog's Heart: Preliminary Communication. The Journal of Physiology, 1895. 18(4): p. 332-333.

12. Tyrode, M.V., Pharmacology1912: P. Blakiston's son \& Company.

13. MICHAELS, I. and K. MUNZEL, [Infusion solutions; Ringer-Tyrode solutions.]. Pharmaceutica acta Helvetiae, 1950. 25(5): p. 153-160.

14. Awad, S., S.P. Allison, and D.N. Lobo, The history of $0.9 \%$ saline. Clinical Nutrition, 2008. 27(2): p. 179-188.

15. Cosnett, J.E., THE ORIGINS OF INTRAVENOUS FLUID THERAPY. The Lancet, 1989. 333(8641): p. 768-771.

16. MacGillivray, N., Dr Thomas Latta: the father of intravenous infusion therapy. Journal of Infection Prevention, 2009. 10(1 suppl): p. s3-s6.

17. The First Use of Intravenous Saline for the Treatment of Disease: Letter from Thomas Latta submitted to the Central Board of Health, London and published in The Lancet, 1832. Preface by Jane Ferrie. International Journal of Epidemiology, 2013. 42(2): p. 387-390.

18. HARTMANN, A.F., Chemical Changes Occurring in the Body as the Result of Certain Diseases: I. The Effects of Diarrhea, Vomiting, Dehydration and Oliguria 
on the Acid-Base Balance of the Plasma of Infants with Mastoiditis. American Journal of Diseases of Children, 1928. 35(4): p. 557-575.

19. Hartmann, A.F., D.C. Darrow, and M. Morton, CHEMICAL CHANGES OCCURRING IN THE BODY AS A RESULT OF CERTAIN DISEASES IN INFANTS AND CHILDREN: II. Acute Hemorrhagic Nephritis. Sub-Acute Nephritis; Severe Chronic Nephritis. Journal of Clinical Investigation, 1928. 6(1): p. 127.

20. Hartmann, A.F., D.C. Darrow, and M. Morton, Chemical Changes Occurring in the Body as the Result of Certain Diseases: III. The Composition of the Plasma in Severe Diabetic Acidosis and the Changes Taking Place During Recovery. Journal of Clinical Investigation, 1928. 6(2): p. 257.

21. Hartmann, A.F., R. Elman, and W.t.T.A.o.M. Morton, THE EFFECTS OF LOSS OF GASTRIC AND PANCREATIC SECRETIONS AND THE METHODS FOR RESTORATION OF NORMAL CONDITIONS IN THE BODY. The Journal of Experimental Medicine, 1929. 50(3): p. 387-405.

22. Hartmann, A.F. and M.J. Senn, studies in the metabolism of sodium R-lactate. I. Response of normal human subjects to the intravenous injection of sodium $R$ lactate. Journal of Clinical Investigation, 1932. 11(2): p. 327.

23. Hartmann, A.F. and M.J. Senn, Studies in the metabolism of sodium r-lactate. II. Response of human subjects with acidosis to the intravenous injection of sodium r-lactate. Journal of Clinical Investigation, 1932. 11(2): p. 337.

24. Hartmann, A.F. and M.J. Senn, Studies in the metabolism of sodium r-lactate. Iii. Response of human subjects with liver damage, disturbed water and mineral balance, and renal insufficiency to the intravenous injection of sodium r-lactate. Journal of Clinical Investigation, 1932. 11(2): p. 345.

25. Kandel, E.R., J.H. Schwartz, and T.M. Jessell, Principles of neural science. Vol. 4. 2000: McGraw-Hill New York.

26. Clarac, F., Neurosciences: From molecule to Behavior: A University Textbook, ed. P.M.L. C. Giovanni Galizia2013: Springer Spektrum.

27. Matthews, G.G., Cellular Physiology of Nerve and Muscle2002: Wiley.

28. Purves, D., ed. NEUROSCIENCE: Third Edition. 2004, Sinauer Associates, Inc.

29. Smith, C.U.M., Elements of Molecular Neurobiology, Third Edition, ed. J.W.S. $\operatorname{Ltd} 2002$.

30. Saladin, K.S., Anatomy \& Physiology: The Unity of Form and Function, ed. G.C.a.S. University2007, New York: McGraw Hill Companies.

31. Jerry Bergman, P.D., ATP: The Perfect Energy Currency for the Cell. Creation Research Society Quarterly, 1999. 36(1).

32. Sperlágh, B. and S.E. Vizi, Neuronal synthesis, storage and release of ATP. Seminars in Neuroscience, 1996. 8(4): p. 175-186.

33. Kuffler, D.P., Neuromuscular transmission in longitudinal muscle of the leech, Hirudo medicinalis. Journal of comparative physiology, 1978. 124(4): p. 333-338.

34. Stuart, A.E., Excitatory and inhibitory motoneurons in the central nervous system of the leech. Science, 1969. 165(3895): p. 817-819. 
35. Stuart, A.E., Physiological and morphological properties of motoneurones in the central nervous system of the leech. The Journal of Physiology, 1970. 209(3): p. 627-646.

36. Muller, K.J., J.G. Nicholls, and G.S. Stent, Neurobiology of the Leech1981, New York: Cold Spring Harbor Laboratory

37. "The Axon Guide", 2008, MDS Analytic Technologies: Sunnyvale, California. 


\section{APPENDICES:}

\section{APPENDIX A}

Ringer's solutions calculations mentioned in Chapter 7:

Below are the calculations used to figure out the amount of $3 \mathrm{M} \mathrm{NaCl}$ needed to make $1 \mathrm{~L}$ of $115 \mathrm{mM} \mathrm{NaCl}$. All subsequent calculations will follow the same two steps.

Step 1, calculate the number of moles of $\mathrm{NaCl}$ needed for a $115 \mathrm{mM}$ solution:

$$
\begin{aligned}
& \mathrm{M}=\frac{\mathrm{m}}{\mathrm{V}} \ldots \ldots \ldots \ldots \ldots \ldots \ldots \ldots \ldots \ldots \ldots \ldots \text { Equation } 4 \\
& .115 \frac{\text { moles }}{\text { liters }}=\frac{\mathrm{m}}{1 \mathrm{~L}} \\
& \mathrm{~m}=.115 \text { moles }
\end{aligned}
$$

Step 2, calculate volume of $3 \mathrm{M} \mathrm{NaCl}$ that gives the number of moles of $\mathrm{NaCl}$ from step 1:

Rearrange Equation 3 to $V=\frac{m}{M}$, and solve for volume.

$$
\begin{gathered}
\text { V liters }=\frac{.115 \text { moles }}{3 \frac{\text { moles }}{\text { liter }}} \\
V=.038 \mathrm{~L} \rightarrow 38 \mathrm{~mL}
\end{gathered}
$$

We need $38 \mathrm{~mL}$ of 3 molar $\mathrm{NaCl}$ in 1 liter of distilled water to make a $115 \mathrm{mM}$ solution. 
Below are the calculations used to figure out the amount of $1 \mathrm{M} \mathrm{CaCl}_{2}$ needed to make $1 \mathrm{~L}$ of $1.8 \mathrm{mM} \mathrm{CaCl}_{2}$.

$$
\begin{gathered}
.0018 \frac{\text { moles }}{\text { liters }}=\frac{\mathrm{m}}{1 \mathrm{~L}} \\
\mathrm{~m}=.0018 \text { moles } \\
\mathrm{V} \text { liters }=\frac{.0018 \mathrm{moles}}{1 \frac{\text { moles }}{\text { liter }}} \\
\mathrm{V}=.0018 \mathrm{~L} \rightarrow 1.8 \mathrm{~mL}
\end{gathered}
$$

We need $1.8 \mathrm{~mL}$ of 1 molar $\mathrm{CaCl}_{2}$ in 1 liter of distilled water to make a $1.8 \mathrm{mM}$ solution.

Below are the calculations used to figure out the amount of $1 \mathrm{M} \mathrm{KCl}$ needed to make $1 \mathrm{~L}$ of $4 \mathrm{mM} \mathrm{KCl}$.

$$
\begin{gathered}
.004 \frac{\text { moles }}{\text { liters }}=\frac{\mathrm{m}}{1 \mathrm{~L}} \\
\mathrm{~m}=.0018 \text { moles } \\
\text { V liters }=\frac{.004 \text { moles }}{1 \frac{\text { moles }}{\text { liter }}} \\
\mathrm{V}=.004 \mathrm{~L} \rightarrow 4 \mathrm{~mL}
\end{gathered}
$$

We need $4 \mathrm{~mL}$ of 1 molar $\mathrm{KCl}$ in 1 liter of distilled water to make a $4 \mathrm{mM}$ solution. 
Below are the calculations used to figure out the amount of $0.2 \mathrm{M}$ Tris maleate needed to make $1 \mathrm{~L}$ of $10 \mathrm{mM} \mathrm{KCl}$.

$$
\begin{gathered}
.01 \frac{\text { moles }}{\text { liters }}=\frac{\mathrm{m}}{1 \mathrm{~L}} \\
\mathrm{~m}=.01 \text { moles } \\
\mathrm{V} \text { liters }=\frac{.01 \mathrm{moles}}{.2 \frac{\text { moles }}{\text { liter }}} \\
\mathrm{V}=.05 \mathrm{~L} \rightarrow 50 \mathrm{~mL}
\end{gathered}
$$

We need $50 \mathrm{~mL}$ of 0.2 molar Tris maleate in 1 liter of distilled water to make a $10 \mathrm{mM}$ solution. 


\section{APPENDIX B}

Proper disposal of leech carcass mentioned in Chapter 8:

1) When leech dissection is complete, leech carcass can be placed in the refrigerator until experimenter is ready to dispose of it.

2) When ready to dispose of leech, use surgical scalpel to cut both the head and tail of the leech where marked in blue in Figure 11.1.

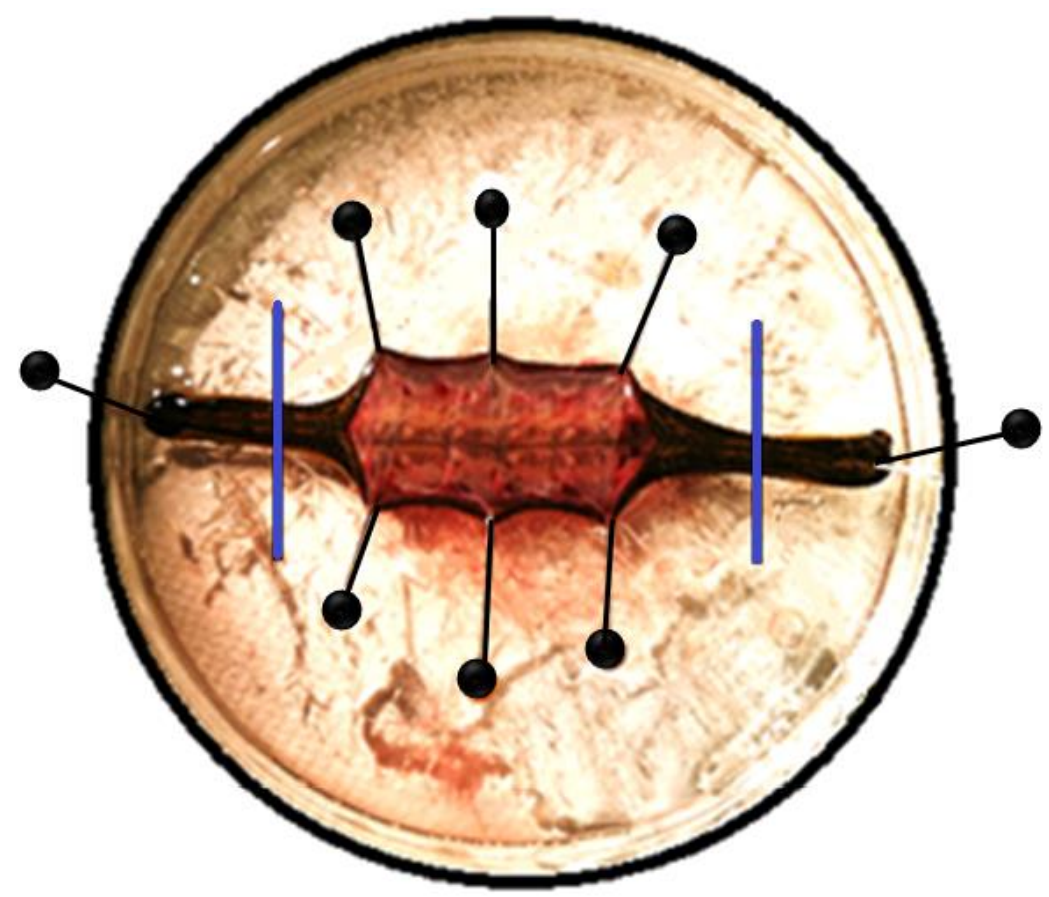

Figure 11.1 Image of leech carcass with blue line indicating cutting points for disposal of leech

3) Remove pins one by one and use paper towel to wipe needles and collect leech parts.

4) Place paper towel containing leech remains in an appropriate freezer with receptacle for biohazards.

5) Rinse Petrie dish well with water and pat/press clean using paper towels.

6) Make sure to wash your hands after handling leech dissection instruments. 


\section{APPENDIX C}

Micropipette pulling instructions mentioned in Chapter 9:

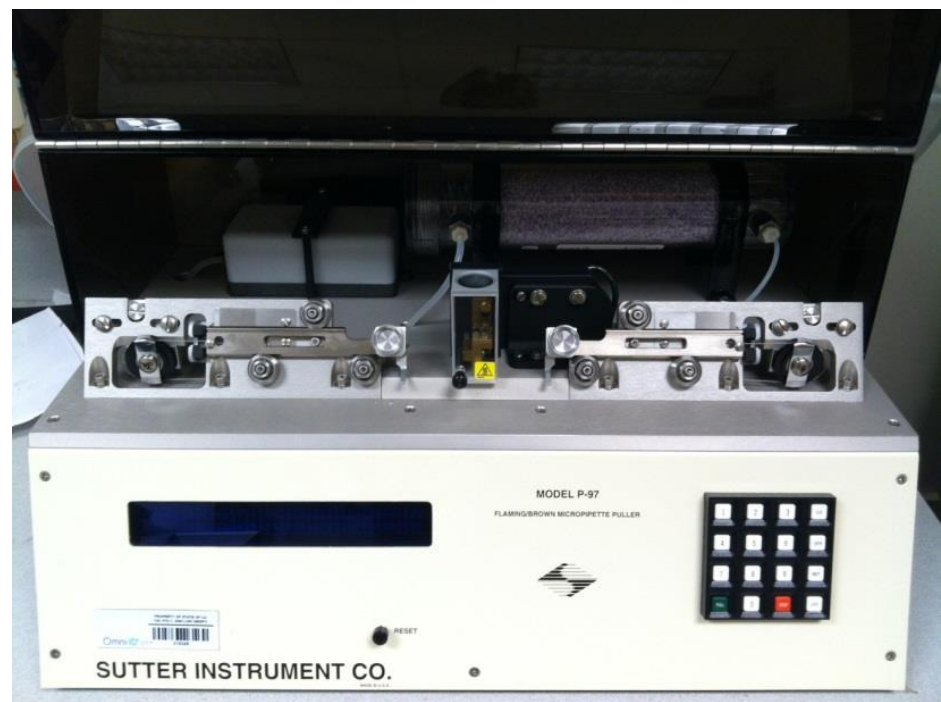

Figure 11.2 Pipette Puller

1. Secure a glass pipette into slot on the right side of the heating components by turning knob until tight. Make sure to push pipette through far enough left to be able to secure other end of pipette with the left knob.

2. Press tabs on both sides to slide knobs together and secure the extended end of the pipette with the left knob.

3. Adjust location of pipette within knobs so that after being pulled about, the pipette remaining on the left side is about 1.5 inches long. 


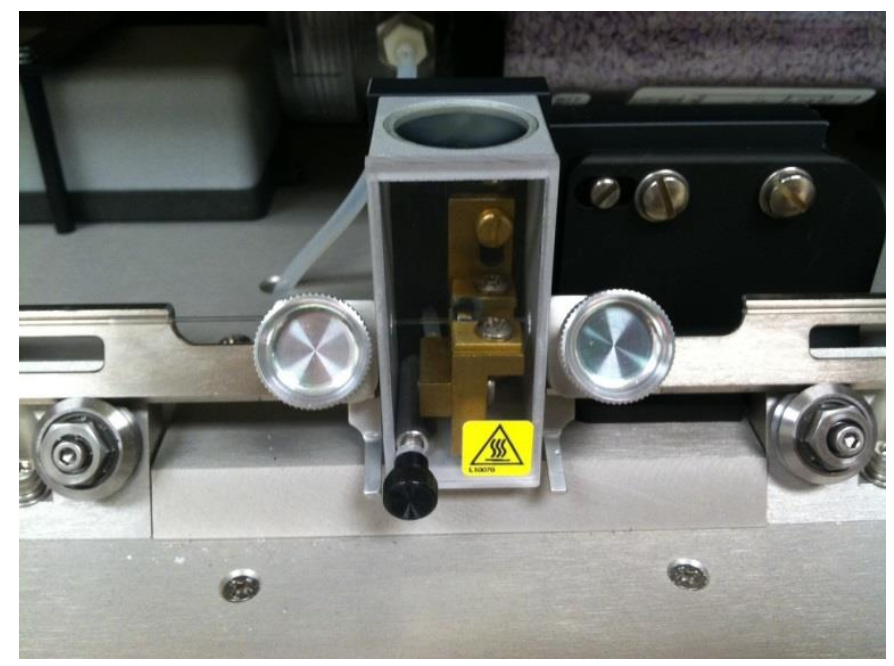

Figure 11.3 Image of glass pipette pushed towards the left and secured by both knobs

4. Power on pipette puller and load program number 33. Settings are already saved into the program $(\mathrm{P}=500$, Heat $=500$, Pull $=95$, Vel. $=80$, Del. $=120)$. If it is found necessary to adjust resistance values provided by these settings, pull and delay and be fine-tuned to increase or decrease resistance. To lower the resistance, decrease pull or increase delay; to increase the resistance, increase pull or decrease delay.

5. Once pipette is properly placed and secured, close lid and press pull. The center heating components will turn red and a loud snap will be heard as the glass is pulled apart.

6. Once pulling is complete, wait until cooling is done (you will feel the light vibration on the machine stop when it is done; about 10 seconds).

7. When cooling is done, open lid and carefully remove pulled pipette without touching the tip! Place in secure pipette holder until ready to use. 

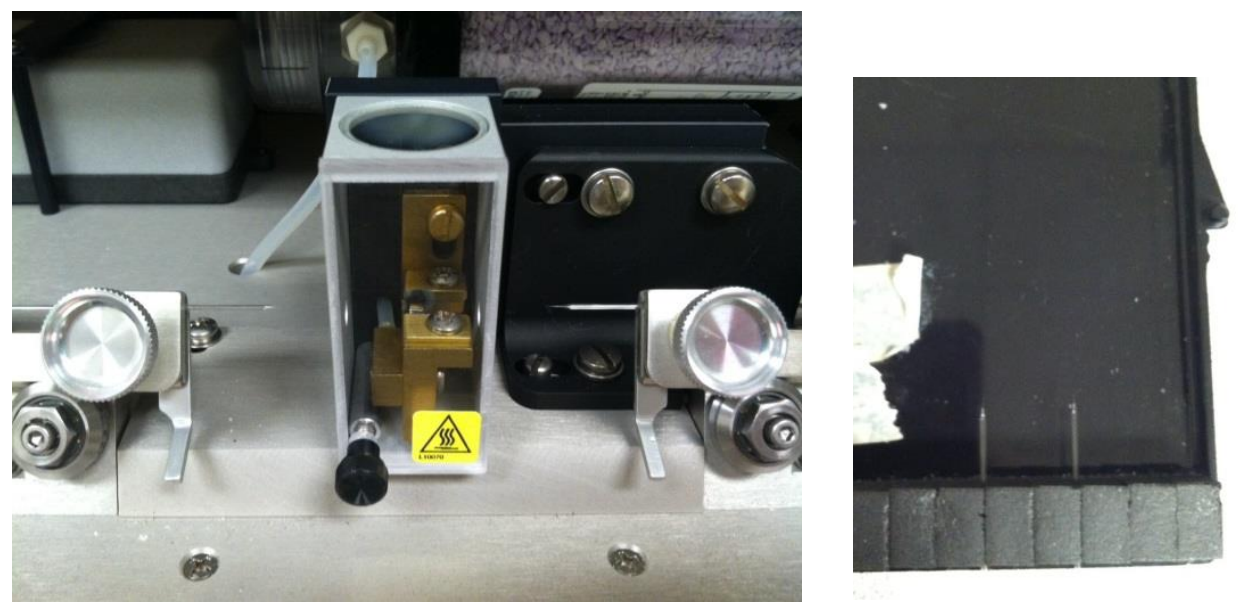

Figure 11.4 A. Pulled pipette B. Pipette tips stored

8. Repeat steps 1-7 with remaining glass from right side. Sharp side must be facing inwards when pulling the second pipette tip.

9. When done pulling, remove any remaining glass and place in appropriate sharps container. Then close the lid and power down the machine. 


\section{APPENDIX D}

Matlab and Minitab Data Analysis mentioned in Chapter 10:

\section{Matlab:}

glucose_avg $=256$

reg_avg $=210.7$

glucose_SD $=47$

reg_SD $=68$

Labels $=\{$ 'Regular Ringers Solution', 'Glucose Ringers Solution' $\}$

figure

bar([reg_avg,glucose_avg],0.5,'displayname',['Ringers','glucose'],'facecolor',[0.8, 0.8, $0.8])$

hold on

set(gca, 'XTick', 1:2, 'XTickLabel', Labels);

errorbar(1:2,[reg_avg,glucose_avg],[reg_SD,glucose_SD],'.','Color','k')

\section{Minitab:}

Descriptive Statistics: total reg ringers, total glucose ringers

Variable $\quad \mathrm{N} \mathrm{N}^{*}$ Mean SE Mean StDev Minimum Median Maximum

$\begin{array}{lllllllll}\text { total reg ringers } & 15 & 0 & 210.7 & 17.6 & 68.0 & 113.0 & 230.0 & 300.0\end{array}$

$\begin{array}{lllllllll}\text { total glucose ringers } & 15 & 0 & 256.0 & 12.1 & 47.0 & 165.0 & 275.0 & 300.0\end{array}$

\section{Paired T-Test and CI: total glucose ringers, total reg ringers}

Paired $\mathrm{T}$ for total glucose ringers - total reg ringers

$\mathrm{N}$ Mean StDev SE Mean

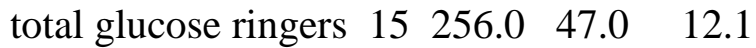

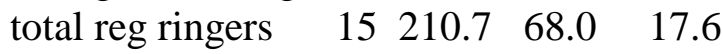

$\begin{array}{lllll}\text { Difference } \quad 15 & 45.3 & 70.4 & 18.2\end{array}$

95\% CI for mean difference: $(6.3,84.3)$

$\mathrm{T}$-Test of mean difference $=0($ vs not $=0): \mathrm{T}$-Value $=2.49 \mathrm{P}$-Value $=0.026$

Paired T-Test and CI: total glucose ringers, total reg ringers

Paired $\mathrm{T}$ for total glucose ringers - total reg ringers

$\mathrm{N}$ Mean StDev SE Mean

total glucose ringers $\begin{array}{llll}15 & 256.0 & 47.0 & 12.1\end{array}$

total reg ringers $\quad \begin{array}{llll}15 & 210.7 & 68.0 & 17.6\end{array}$

$\begin{array}{lllll}\text { Difference } & 15 & 45.3 & 70.4 & 18.2\end{array}$

95\% lower bound for mean difference: 13.3

T-Test of mean difference $=30(\mathrm{vs}>30)$ : $\mathrm{T}$-Value $=0.84 \mathrm{P}-\mathrm{V}$ alue $=0.207$ 


\section{Regression Analysis: total reg ringers versus numb of stims}

The regression equation is

total reg ringers $=221-0.127$ numb of stims

Predictor Coef SE Coef T P

$\begin{array}{lllll}\text { Constant } & 220.51 & 40.09 & 5.50 & 0.000\end{array}$

numb of stims $-0.1270 \quad 0.4609 \quad-0.28 \quad 0.787$

$\mathrm{S}=70.3940 \quad \mathrm{R}-\mathrm{Sq}=0.6 \% \quad \mathrm{R}-\mathrm{Sq}(\operatorname{adj})=0.0 \%$

Analysis of Variance

Source DF SS MS F $P$

$\begin{array}{llllll}\text { Regression } \quad 1 & 376 & 376 & 0.08 & 0.787\end{array}$

Residual Error 13644194955

Total 1464795

Unusual Observations numb of total reg

Obs stims ringers Fit SE Fit Residual St Resid

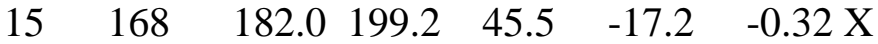

$\mathrm{X}$ denotes an observation whose $\mathrm{X}$ value gives it large leverage.

Regression Analysis: total glucose ringers versus numb of stims

The regression equation is

total glucose ringers $=225+0.402$ numb of stims

Predictor Coef SE Coef T P

Constant $224.83 \quad 26.04 \quad 8.64 \quad 0.000$

numb of stims $0.4020 \quad 0.2993 \quad 1.34 \quad 0.202$

$\mathrm{S}=45.7105 \quad \mathrm{R}-\mathrm{Sq}=12.2 \% \quad \mathrm{R}-\mathrm{Sq}(\mathrm{adj})=5.4 \%$

Analysis of Variance

Source DF SS MS F P

$\begin{array}{llllll}\text { Regression } \quad 1 \quad 3769 & 3769 & 1.80 & 0.202\end{array}$

Residual Error 13271632089

Total 1430932

Unusual Observations total

numb of glucose

Obs stims ringers Fit SE Fit Residual St Resid

$\begin{array}{lllllll}1 & 83 & 165.0 & 258.2 & 11.9 & -93.2 & -2.11 \mathrm{R}\end{array}$

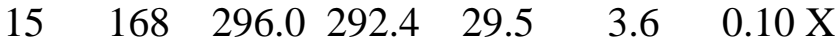

$\mathrm{R}$ denotes an observation with a large standardized residual.

$\mathrm{X}$ denotes an observation whose $\mathrm{X}$ value gives it large leverage. 
Two-Sample T-Test and CI: total reg ringers, HS

Two-sample $\mathrm{T}$ for total reg ringers

SE

HS N Mean StDev Mean

$\begin{array}{lllll}0 & 8 & 227.4 & 66.9 & 24\end{array}$

$\begin{array}{lllll}1 & 7 & 191.6 & 69.1 & 26\end{array}$

Difference $=\mathrm{mu}(0)-\mathrm{mu}(1)$

Estimate for difference: 35.8

95\% CI for difference: $(-41.0,112.6)$

$\mathrm{T}$-Test of difference $=0($ vs not $=): \mathrm{T}-$ Value $=1.02 \mathrm{P}-$ Value $=0.330 \mathrm{DF}=12$

Two-Sample T-Test and CI: total glucose ringers, HS

Two-sample $\mathrm{T}$ for total glucose ringers

HS N Mean StDev SE Mean

$\begin{array}{lllll}0 & 8 & 248.4 & 52.0 & 18\end{array}$

$\begin{array}{lllll}1 & 7 & 264.7 & 42.9 & 16\end{array}$

Difference $=\mathrm{mu}(0)-\mathrm{mu}(1)$

Estimate for difference: -16.3

95\% CI for difference: $(-69.7,37.0)$

$\mathrm{T}$-Test of difference $=0($ vs not $=)$ : T-Value $=-0.67 \mathrm{P}-$ Value $=0.517 \mathrm{DF}=12$ 